\title{
THE SOLUTION OF SIMULTANEOUS EQUATIONS
}

\author{
P. S. DWYER \\ UNIVERSITY OF MICHIGAN
}

\begin{abstract}
This paper is an attempt to integrate the various methods which have been developed for the numerical solution of simultaneous linear equations. It is demonstrated that many of the common methods, including the Doolittle Method, are variations of the method of "single division." The most useful variation of this method, in case symmetry is present, appears to be the Abbreviated Doolittle method. The method of multiplication and subtraction likewise can be abbreviated in various ways of which the most satisfactory form appears to be the new Compact method. These methods are then applied to such problems as the solution of related equations, the solution of groups of equations, and the evaluation of the inverse of a matrix.
\end{abstract}

\section{Introduction}

During recent years various articles have appeared, (1) (2) (3) (4), on the general topic of the solution of normal equations. At first thought it appears that articles of this type are not needed since the theory of determinants gives the desired solution, but further invesvestigation reveals that classical determinantal methods, excellent for theoretical purposes, are not the most efficient tools for determining numerical solutions when the number of variables is large. The improvement of the modern calculating machine (in particular the introduction of automatic division and automatic multiplication) has made available methods which, though algebraically simple, were previously numerically cumbersome. It appears now that the new numerical methods have been developed sufficiently so that the presentation of a rather thorough treatment of them, and of their relations to each other, is wise. From such an analysis we are able to arrive at new and more compact methods. It should be specified also that we are not at present investigating iterative nor determinantal methods, though the methods outlined in this paper can be used in evaluating determinants.

In many of the problems in which the approximate solution of a large number of equations is desired, the simultaneous equations are symmetric with respect to the coefficients of the unknowns (i.e., the matrix of the coefficients of the unknowns is symmetric). For example, if the equations are 


$$
\begin{aligned}
& a_{41} x_{1}+a_{21} x_{2}+a_{31} x_{3}+a_{41} x_{4}=a_{51} \\
& a_{22} x_{1}+a_{22} x_{2}+a_{32} x_{3}+a_{42} x_{4}=a_{52} \\
& a_{33} x_{1}+a_{23} x_{2}+a_{33} x_{3}+a_{45} x_{4}=a_{53} \\
& a_{34} x_{1}+a_{24} x_{2}+a_{34} x_{3}+a_{44} x_{4}=a_{54}
\end{aligned}
$$

then, frequently $a_{i j}=a_{j i}$. This is always true, of course, if the equations are normal equations or their equivalents. This symmetry, if present, simplifies the resulting techniques. In the present article we give the techniques for the general situation and also the specialized techniques in case symmetry is present.

The methods outlined apply to the solution of $n$ equations in $n$ unknowns. In the interest of brevity, however, we use but four equations in four unknowns, equations (1), to present the theory. The solutions are not more complicated, just longer, when more than four variables are involved.

Each of the methods presented is illustrated by application to the equations

$$
\begin{array}{r}
x_{1}+.4 x_{2}+.5 x_{3}+.6 x_{4}=.2 \\
.4 x_{1}+1.0 x_{2}+.3 x_{3}+.4 x_{4}=.4 \\
.5 x_{1}+.3 x_{2}+1.0 x_{3}+.2 x_{1}=.6 \\
.6 x_{1}+.4 x_{2}+.2 x_{3}+1.0 x_{4}=.8
\end{array}
$$

where the $a$ 's are exact values. The solutions in this case are then carried to five significant figures or to four decimal places. All solutions are indicated symbolically in the tables where no $x$ 's appear explicit$\mathrm{ly}$, but the first column presents the coefficients of the $x_{1}$, the second of $x_{2}$, etc. The last column is the conventional check column giving the sum of the entries in the row.

\section{Method One. The Method of Division}

The first method described, which is essentially that given in Huntington's article in the "Handbook of Mathematical Statistics" $(5$, p. 67), we might call the method of division. Each equation is divided by its leading coefficient and some equation, say the first, is subtracted in turn from each of the $n-1$ others giving a new set of $n-1$ equations in $n-1$ uniknowns. The process is repeated until one equation in one unknown is obtained. The back solution is then readily obtained by substitution. 
TABLE 1. METHOD OF DIVISION

\begin{tabular}{|c|c|c|c|c|c|c|c|c|c|c|c|}
\hline \multicolumn{6}{|c|}{ General } & \multicolumn{5}{|c|}{ Illustration } & \multirow[b]{2}{*}{ check } \\
\hline$x_{1}$ & $x_{2}$ & $x_{3}$ & $x_{4}$ & & check & $x_{1}$ & $x_{2}$ & $x_{3}$ & $x_{4}$ & & \\
\hline $\begin{array}{l}a_{11} \\
a_{12} \\
a_{13} \\
a_{14}\end{array}$ & $\begin{array}{l}a_{21} \\
a_{22} \\
a_{23} \\
a_{21}\end{array}$ & $\begin{array}{l}a_{31} \\
a_{32} \\
a_{33} \\
a_{34}\end{array}$ & $\begin{array}{l}a_{41} \\
a_{42} \\
a_{43} \\
a_{44}\end{array}$ & $\begin{array}{l}a_{51} \\
a_{52} \\
a_{53} \\
a_{58}\end{array}$ & $\begin{array}{l}a_{61} \\
a_{62} \\
a_{63} \\
a_{64}\end{array}$ & $\begin{array}{r}1.0000 \\
.4000 \\
.5000 \\
.6000\end{array}$ & $\begin{array}{r}.4000 \\
1.0000 \\
.3000 \\
.4000\end{array}$ & $\begin{array}{r}.5000 \\
.3000 \\
1.0000 \\
.2000\end{array}$ & $\begin{array}{r}.60000 \\
.40000 \\
.20000 \\
1.00000\end{array}$ & $\begin{array}{l}.2000 \\
.4000 \\
.6000 \\
.8000\end{array}$ & $\begin{array}{l}2.7000 \\
2.5000 \\
2.6000 \\
3.0000\end{array}$ \\
\hline $\begin{array}{l}1 \\
1 \\
1 \\
1\end{array}$ & $\begin{array}{l}b_{23} \\
b_{22} \\
b_{23} \\
b_{24}\end{array}$ & $\begin{array}{l}b_{31} \\
b_{32} \\
b_{33} \\
b_{34}\end{array}$ & $\begin{array}{l}b_{41} \\
b_{42} \\
b_{43} \\
b_{44}\end{array}$ & $\begin{array}{l}b_{52} \\
b_{52} \\
b_{53} \\
b_{54}\end{array}$ & $\begin{array}{l}b_{61} \\
b_{62} \\
b_{63} \\
b_{64}\end{array}$ & $\begin{array}{l}1.0000 \\
1.0000 \\
1.0000 \\
1.0000\end{array}$ & $\begin{array}{r}.4000 \\
2.5000 \\
.6000 \\
.6667\end{array}$ & $\begin{array}{r}.5000 \\
.7500 \\
2.0000 \\
.3333\end{array}$ & $\begin{array}{r}.6000 \\
1.0000 \\
.4000 \\
1.6667\end{array}$ & $\begin{array}{r}.2000 \\
1.0000 \\
1.2000 \\
1.3333\end{array}$ & $\begin{array}{l}2.7000 \\
6.2500 \\
5.2000 \\
5.0000\end{array}$ \\
\hline & $\begin{array}{l}a_{22.1}^{\prime} \\
a_{23.1}^{\prime} \\
a_{24.1}^{\prime}\end{array}$ & $\begin{array}{l}a_{32.1}^{\prime} \\
a_{33.1}^{\prime} \\
a_{34.1}^{\prime}\end{array}$ & & $\begin{array}{l}a_{52.1}^{\prime} \\
a_{53.1}^{\prime} \\
a_{E 4.1}^{\prime}\end{array}$ & $\begin{array}{l}a_{62.1}^{\prime} \\
a_{68.1}^{\prime} \\
a_{64.1}^{\prime}\end{array}$ & & $\begin{array}{r}2.1000 \\
.2000 \\
.2667\end{array}$ & $\begin{array}{r}.2500 \\
1.5000 \\
-.1667\end{array}$ & $\begin{array}{r}.4000 \\
-.2000 \\
1.0667\end{array}$ & $\begin{array}{r}.8000 \\
1.0000 \\
1.1333\end{array}$ & $\begin{array}{l}3.5500 \\
2.5000 \\
2.3000\end{array}$ \\
\hline & $\begin{array}{l}1 \\
1 \\
1 \\
\end{array}$ & $\begin{array}{l}b_{32.1}^{\prime} \\
b_{33.2}^{\prime} \\
b_{34.1}^{\prime} \\
\end{array}$ & $\begin{array}{l}b^{\prime} \\
b^{\prime}=2.1 \\
b^{\prime} \\
4.1 .1\end{array}$ & $\begin{array}{l}b_{52.1}^{\prime} \\
b_{53.1}^{\prime} \\
b_{54.1}^{\prime}\end{array}$ & $\begin{array}{l}b_{62.1}^{\prime} \\
b_{68.1}^{\prime} \\
b_{64.1}^{\prime}\end{array}$ & & $\begin{array}{l}1.0000 \\
1.0000 \\
1.0000\end{array}$ & $\begin{array}{r}.1190 \\
7.5000 \\
-.6250\end{array}$ & $\begin{array}{r}.1905 \\
-1.0000 \\
3.9996\end{array}$ & $\begin{array}{r}.3810 \\
5.0000 \\
4.2493\end{array}$ & $\begin{array}{r}1.6905 \\
12.5000 \\
8.6239\end{array}$ \\
\hline & & $\begin{array}{l}a_{33.12}^{\prime} \\
a_{34.12}^{\prime}\end{array}$ & & $\begin{array}{l}a_{53.12}^{\prime} \\
a^{\prime}{ }_{56.12}\end{array}$ & $\begin{array}{l}a_{68.12}^{\prime} \\
a_{86.12}^{\prime}\end{array}$ & & & $\begin{array}{l}7.3810 \\
-.7440\end{array}$ & $\begin{array}{r}-1.1905 \\
3.8091\end{array}$ & $\begin{array}{l}4.6190 \\
3.8683\end{array}$ & $\begin{array}{r}10.8095 \\
6.9334\end{array}$ \\
\hline & & $\begin{array}{l}1 \\
1\end{array}$ & $\begin{array}{l}b^{\prime} \\
b^{\prime 3.12} \\
a_{4.123}^{\prime}\end{array}$ & $\begin{array}{l}b_{53.12}^{\prime} \\
b_{54.12}^{\prime} \\
a_{54.123}^{\prime}\end{array}$ & $\begin{array}{l}b_{63.12}^{\prime} \\
b_{64.12}^{\prime} \\
a_{64.123}^{\prime}\end{array}$ & & & $\begin{array}{l}1.0000 \\
1.000\end{array}$ & $\begin{array}{r}-.1613 \\
-5.1198 \\
-4.9585\end{array}$ & $\begin{array}{r}.6258 \\
-5.1993 \\
-5.8251\end{array}$ & $\begin{array}{r}1.4645 \\
-9.3191 \\
-10.7836\end{array}$ \\
\hline 1 & 1 & 1 & 1 & $\begin{array}{l}b_{54.123}^{\prime} \\
b^{\prime} \\
b_{53.124}^{\prime} \\
b_{52.134}^{\prime} \\
{ }_{51.234}\end{array}$ & $\begin{array}{l}b_{64.123}^{\prime} \\
b_{63.124}^{\prime} \\
b_{62.134}^{\prime} \\
b_{61.234}^{\prime}\end{array}$ & 1.0000 & 1.0000 & 1.0000 & 1.0000 & $\begin{array}{r}1.1748 \\
.8153 \\
.0602 \\
-.9366\end{array}$ & $\begin{array}{r}2.1748 \\
1.8153 \\
1.0602 \\
.0634\end{array}$ \\
\hline
\end{tabular}

The solution of (1) is given at the left of Table 1 while the fourdecimal-place approximation to the solution of $(2)$ is given at the right. If we refer to each main subdivision of the table as a "matrix," we may say that the first matrix denotes the equations. The second matrix denotes the equations resulting when each has been divided by its leading coefficient. The third matrix results from subtracting the first equation from the others. Thus $a_{22.1}^{\prime}=b_{22}-b_{21}$, and in the illustration $2.1000=2.5000-.4000$. This process is then continued until one equation in one unknown results and $x_{4}=b^{\prime}{ }_{54.123}$. Now since $x_{3}+b^{\prime}{ }_{43.12} x_{4}=b_{53.12}^{\prime}$, it follows that $x_{3}=b_{53.12}^{\prime}-b^{\prime}{ }_{43.12} b^{\prime}{ }_{54.123}$, and the value $x_{3}=b^{\prime}{ }_{53.124}$ can be obtained from the entries in the first row of the sixth matrix and the $x_{4}$ previously obtained. Thus from $b_{53.22}^{\prime}$ we subtract the product of $b^{\prime}{ }_{43.12}$ and the entry to the right of the "one" in the last matrix, $b^{\prime}{ }_{54.123}$. This result may be checked by using the second row of matrix 6 with the resulting 


$$
b^{\prime}{ }_{53.124}=b^{\prime}{ }_{54.12}-b_{44.12}^{\prime} b^{\prime}{ }_{54.123} \text {. }
$$

Similarly, using the first row of matrix 4

$$
b^{\prime}{ }_{52.134}=b_{52.1}^{\prime}-b^{\prime}{ }_{2.1} b_{54.123}^{\prime}-b_{32.1}^{\prime} b_{53.124}^{\prime} \text {, }
$$

etc. This process is carried out easily from the entries of the table once the "ritual" is learned.

The check column, column 6 , is handled just as column 5 , though column 5 is not involved in the back solution. Thus $b_{63.124}^{\prime}=b^{\prime}{ }_{63.12}$ $-b^{\prime}{ }_{43.12} b_{64.128}$. The check results from the fact that, for every row in every matrix, the entry in column 6 is the sum of the entries in the columns to the left.

This methor is the least satisfactory (aside from its theoretical simplicity) of the various methods presented. The symmetry of the equations, if originally present, is lost with the first set of divisions. Many divisions are demanded and the method utilizes $n(n+1)+\mathrm{n}-$ $1=(n+1)^{2}-2$ rows. In general the method will give approximations since divisions are involved.

Brolyer (6) and Chauncey (7) have shown how this method may be simplified by the elimination of considerable recording and some computing. The even-numbered matrices in Table 1 are replaced by a single row which is placed directly under the equation from which it was obtained. The processes of division and subtraction are then performed in one operation with the use of $(a / b)-c$ techniques. The number of rows in the forward and back solution is reduced to $\frac{(n+1)(n+2)}{2}+n-2=\frac{n(n+5)}{2}-1$. If $a_{11}=1$, the first division row is not needed and we have $\frac{n(n+5)}{2}-2$ rows.

\section{Method Two. The Method of Single Division}

The method of single division is characterized by the leading element in the case of but one of the $n$ equations. The resulting equation is then combined with each of the $n-1$ other equations in turn to give $n-1$ equations in $n-1$ unknowns. The new equation can be written at the bottom of the $n$ equations. There is no great loss in generality and a somewhat simpler technique results if the variables are eliminated in 1,2,3,4, order, (divide the top row of each matrix by its leading coefficient), though a somewhat more complicated technique can be worked out if no such restriction is made. It is necessary that this leading coefficient be different from 0 . 
The method is derived by the elimination of $x_{1}$ from each of the last three equations of (1),

$$
a_{1 j} x_{1}+a_{2 j} x_{2}+a_{3 j} x_{3}+a_{4 j} x_{4}=a_{5 j}, \quad j=2,3,4
$$

and from the first equation of (1) divided by its leading coefficient,

$$
x_{1}+b_{21} x_{2}+b_{31} x_{3}+b_{41} x_{4}=b_{51} \text {. }
$$

We multiply (4) by $a_{1 j}$ and subtract from (3) to get

$$
\left(a_{2 j}-a_{1 j} b_{21}\right) x_{2}+\left(a_{3 j}-a_{1 j} b_{31}\right) x_{3}+\left(a_{4 j}-a_{1 j} b_{41}\right) x_{4}=a_{5 j}-a_{1 j} b_{31} \text {, }
$$

which can be written

$$
a_{2 j .1} x_{2}+a_{3 j .1} x_{3}+a_{4 j .1} x_{4}=a_{5 j .1}, \quad j=2,3,4 \text {. }
$$

The process is repeated to eliminate $x_{2}, x_{3}$, etc., in turn.

Thus

$$
a_{3 j, 12} x_{3}+a_{4 j, 12} x_{4}=a_{5 j, 12},
$$

with $a_{i j .12}=a_{i j .1}-a_{2 j, 1} b_{i 2.1}$.

\begin{tabular}{|c|c|c|c|c|c|c|c|c|c|c|c|}
\hline \multicolumn{6}{|c|}{ General } & \multicolumn{5}{|c|}{ Illustration } & \multirow[b]{2}{*}{ check } \\
\hline$x_{1}$ & $x_{2}$ & $x_{3}$ & $x_{4}$ & & check & $x_{1}$ & $x_{2}$ & $x_{3}$ & $x_{4}$ & & \\
\hline \multirow{16}{*}{$\begin{array}{l}a_{11} \\
a_{1:} \\
a_{13} \\
a_{14} \\
1\end{array}$} & $a_{21}$ & $a_{32}$ & $a_{41}$ & $a_{52}$ & $a_{61}$ & 1.0000 & .4000 & .5000 & .6000 & .2000 & 2.7000 \\
\hline & $a_{22}$ & $a_{32}$ & $a_{42}$ & $a_{52}$ & $a_{02}$ & .4000 & 1.0000 & .3000 & .4000 & .4000 & 2.5000 \\
\hline & $a_{33}$ & $a_{33}$ & $a_{43}$ & $a_{53}$ & $a_{\hat{6} 3}$ & .5000 & .3000 & 1.0000 & .2000 & .6000 & 2.6000 \\
\hline & $a_{24}$ & $a_{34}$ & $a_{44}$ & $a_{54}$ & $a_{64}$ & .6000 & .4000 & .2000 & 1.0000 & .8000 & 2.0000 \\
\hline & $b_{21}$ & $b_{31}$ & $b_{11}$ & $b_{51}$ & $b_{61}$ & 1.0000 & .4000 & .5000 & .6000 & .2000 & 2.7000 \\
\hline & $a_{22,1}$ & $a_{32,1}$ & $a_{42.1}$ & $a_{52.1}$ & $b_{62.1}$ & & .8400 & .1000 & .1600 & .3200 & 1.4200 \\
\hline & $a_{23.1}$ & $a_{3 s .1}$ & $a_{43.1}$ & $a_{53.1}$ & $a_{63.1}$ & & .1000 & .7500 & -.1000 & .5000 & 2500 \\
\hline & $a_{24.1}$ & $a_{34.1}$ & $a_{14.3}$ & $a_{34.1}$ & $a_{64.1}$ & & .1600 & -.1000 & .6400 & .6800 & 1.3800 \\
\hline & 1 & $b_{32.1}$ & $b_{42.1}$ & $b_{52.1}$ & $b_{61.1}$ & & 1.0000 & .1190 & .1905 & .3810 & 1.6805 \\
\hline & & $a_{33.12}$ & $a_{43.12}$ & $a_{53.12}$ & $a_{63.12}$ & & & .7381 & -.1190 & .4619 & 1.0810 \\
\hline & & $a_{34.12}$ & $a_{44.12}$ & $a_{54.12}$ & $a_{64,12}$ & & & -.1190 & .6095 & .6190 & 1.1095 \\
\hline & & & $b_{43.12}$ & $b_{53.12}$ & $b_{63.12}$ & & & 1.0000 & -.1612 & .6258 & 1.4646 \\
\hline & & & $a_{14.123}$ & $a_{54,123}$ & $a_{64.123}$ & & & & .5903 & .6935 & 1.2838 \\
\hline & & & 1 & $b_{54.123}$ & $b_{64 .}$ & & & & 1.0000 & 1.1748 & 2.1745 \\
\hline & & 1 & & $b_{53.124}$ & $b_{63}$ & & & 1.0000 & & .8152 & 1.8152 \\
\hline & 1 & & & $b_{52.134}$ & $b_{62.134}$ & & 1.0000 & & & .0602 & 1.0602 \\
\hline 1 & & & & $b_{51.234}$ & $b_{51.234}$ & 1.0000 & & & & -.9366 & .0634 \\
\hline
\end{tabular}

The forward technique is simple. Divide the first row in any matrix by its leading coefficient to form the last row in the matrix. Take any element in the matrix and subtract the product of its lead-

TABLE 2. METHOD OF SINGLE DIVISION 
ing row element and its bottom columnar element and the result is the proper entry for the corresponding place in the next matrix. The solution of (1), with the added check column, is shown in Table 2.

This method, essentially, has been given by Deming (8), who did not restrict the order of elimination. It has also been given, essentially, by Aitken (9) who calls it the "Method of pivotal condensation," though Aitken placed the divided row at the top of the matrix.

The back solution is obtained by subtraction. Thus $b_{\text {ss.xes }}$ is obtained by substituting $x_{4}=b_{54.123}$ in the equation $x_{3}+b_{43.12} x_{4}=b_{32.12}$ so that $x_{3}=b_{33.22}-b_{43.12} b_{54.123}$. This is easily done since it is only necessary to record $b_{\text {ss.nz }}$ and subtract from it the product of the term before it $\left(b_{\text {Lx.22 }}\right)$ and the term associated with the "one" below it $\left(b_{53.124}\right)$. Similarly the computation of $b_{52.134}=b_{52.1}-b_{12.1} b_{54.123}-$ $b_{32.1} b_{33.224}$ can be reduced to a simple ritual.

This method is much preferable to the method of division in that fewer divisions and subtractions are required and there is less recording. Also this solution demands but $\frac{n^{2}+5 n-2}{2}$ rows for the forward and back solutions. Furthermore this solution retains symmetry, if originally present, for if $a_{i j}=a_{j i}$, then

$$
\begin{aligned}
& a_{i j .1}=a_{i j}-a_{1 j} b_{i 1}=a_{i j}-\frac{a_{1 j} a_{i 1}}{a_{11}}=a_{j i .1}, \\
& a_{i j .12}=a_{j i .22}, \text { etc. }
\end{aligned}
$$

This symmetry has not been used (though it could be used for checking) in the foregoing method so that this method is applicable to nonsymmetric equations.

\section{Method Three. Method of Single Division-Symmetric}

This method is essentially a special case of the method above though some adjustments are needed because of deleted entries. It is not necessary to record both $a_{i j}$ and $a_{j i}$. since they are equal if $a_{i j}=$ $a_{j i}$. We hence omit all the entries below the main diagonal for each matrix. For example, in Table 2 we omit all the entries to the left of and below the main diagonal. A dash (-) is used to indicate the omission, rather than the vanishing, of these entries.

However, we have been using the entries at the left of the table in computing the entries in the next matrix and so we still have to find the equivalent of these entries. Now a duplicate of the leading term for each row is obtained by going along the row to the main 
diagonal and then taking the heading of that column, since $a_{i j}=a_{j i}$. In this manner the subtracted product is obtained from the first and last rows of each matrix. The entry from the last row is the entry at the foot of the column, while the entry from the top row is obtained by moving along the row which contains the element to the main diagonal of the matrix and then taking the heading of that column. Thus

and in Table 2

$$
a_{i j .1}=a_{i j}-b_{i 1} a_{j n},
$$

Similarly,

$$
a_{34.1}=(.2000)-(.5000)(.6000)=-.1000 .
$$

$$
a_{34.12}=(-.1000)-(.1000)(.1905)=-.1190 \text {. }
$$

The back solution is similar to that of method 2. The technique is easily learned with a little practice. The solution of (1) is presented

\begin{tabular}{|c|c|c|c|c|c|c|c|c|c|c|c|}
\hline \multicolumn{4}{|c|}{ General } & & & \multicolumn{4}{|c|}{ Illustration } & & \multirow[b]{2}{*}{ check } \\
\hline$x_{1}$ & $x_{2}$ & $x_{3}$ & $x_{4}$ & & check & $x_{1}$ & $x_{2}$ & $x_{3}$ & $x_{4}$ & & \\
\hline \multirow[t]{5}{*}{$\frac{a_{11}}{-}$} & $\begin{array}{l}a_{21} \\
a_{22} \\
= \\
-\end{array}$ & $\begin{array}{l}a_{31} \\
a_{32} \\
a_{33} \\
\frac{b_{31}}{a_{31}}\end{array}$ & $\begin{array}{l}a_{41} \\
a_{42} \\
a_{43} \\
a_{44} \\
b_{41}\end{array}$ & $\begin{array}{l}a_{51} \\
a_{52} \\
a_{53} \\
a_{54} \\
b_{51}\end{array}$ & $\begin{array}{l}a_{61} \\
a_{62} \\
a_{63} \\
a_{64} \\
b_{61}\end{array}$ & $\begin{array}{c}1.0000 \\
- \\
\overline{1.0000}\end{array}$ & $\begin{array}{c}.4000 \\
1.0000 \\
- \\
.4000\end{array}$ & $\begin{array}{c}.5000 \\
.3000 \\
1.0000 \\
.5000\end{array}$ & $\begin{array}{r}.6000 \\
.4000 \\
.2000 \\
1.0000 \\
.6000\end{array}$ & $\begin{array}{l}.2000 \\
.4000 \\
.6000 \\
.8000 \\
.2000\end{array}$ & $\begin{array}{l}2.7000 \\
2.5000 \\
2.6000 \\
3.0000 \\
2.7000\end{array}$ \\
\hline & $\frac{a_{22.1}}{1}$ & $\begin{array}{l}a_{32.1} \\
a_{33.1} \\
- \\
b_{32.1}\end{array}$ & $\begin{array}{l}a_{42.1} \\
a_{43.1} \\
a_{44.1} \\
b_{42.1} \\
\end{array}$ & $\begin{array}{l}a_{52.3} \\
a_{53.1} \\
a_{54.1} \\
b_{52.1}\end{array}$ & $\begin{array}{l}a_{62.1} \\
a_{63.1} \\
a_{64.1} \\
b_{62.1}\end{array}$ & & $\frac{.8400}{\overline{-}}$ & $\begin{array}{c}.1000 \\
.7500 \\
-1190\end{array}$ & $\begin{array}{r}.1600 \\
-.1000 \\
.6400 \\
.1905\end{array}$ & & $\begin{array}{l}1.4200 \\
1.2500 \\
1.3800 \\
1.6905\end{array}$ \\
\hline & & $\frac{a_{33.12}}{1}$ & $\begin{array}{l}a_{43.12} \\
a_{44.12} \\
b_{43.12} \\
\end{array}$ & $\begin{array}{l}a_{53.12} \\
a_{54.12} \\
b_{53.12}\end{array}$ & $\begin{array}{l}a_{63.12} \\
a_{64.12} \\
b_{63.12}\end{array}$ & & & $\frac{.7381}{1.0000}$ & $\begin{array}{r}-.1190 \\
.6095 \\
-.1612 \\
\end{array}$ & $\begin{array}{l}.4619 \\
.6190 \\
.6258 \\
\end{array}$ & $\begin{array}{l}1.0810 \\
1.1095 \\
1.4646 \\
\end{array}$ \\
\hline & & & $a_{44.123}$ & $a_{54.138}$ & $a_{64.123}$ & & & & .5903 & .6935 & 1.2838 \\
\hline & 1 & 1 & 1 & $\begin{array}{l}b_{54.123} \\
b_{53.124} \\
b_{52.134} \\
b_{51.234}\end{array}$ & $\begin{array}{l}b_{64.123} \\
b_{63.124} \\
b_{62.134} \\
b_{61.294}\end{array}$ & 1.0000 & 1.0000 & 1.0000 & 1.0000 & $\begin{array}{r}1.1748 \\
.8152 \\
.0602 \\
-.9366\end{array}$ & $\begin{array}{r}2.1748 \\
1.8152 \\
1.0602 \\
.0634\end{array}$ \\
\hline
\end{tabular}
in Table 3.

TABLE 3. METHOD OF SINGLE DIVISION-SYMMETRIC

The check column entry is not necessarily equal to the sum of the entries in the row since some of these entries are not recorded, but in such a case it is equal to the sum of the entries as far left as the main diagonal plus those in the column to the top of the matrix. Thus $a_{64.7}=a_{54.1}+a_{44.1}+a_{43.1}+a_{42.1}$. 
The method demands the same number of rows as method 2, but there are fewer entries and computations. The back solutions are the same.

\section{Method Four. Abbreviated Method of Single Division}

An alternative condensation of method, which can be used whether the equations are symmetric or not, is the abbreviated method of single division which demands less recording than the method of single division. The method consists in computing and recording the entries for the first row and for the first column only of each new matrix. These entries are then used, along with the first rows and columis of previous matrices, to compute entries for the first row and for the first column of the next matrix. For we can write

$$
\begin{aligned}
a_{i j .1} & =a_{i j}-a_{1 j} b_{i 1}, \\
a_{i j .32} & =a_{i j .1}-a_{i j .3} b_{i 2.1}=a_{i j}-a_{1 j} b_{i 1}-a_{2 j .3} b_{i 2.1 .} \text {, etc. }
\end{aligned}
$$

It is necessary to compute these values only as needed. A little practice will enable one to use this method easily. Thus, in Table 4.

$$
\begin{aligned}
a_{44.123}=1.000-(.6000)(.6000)-(.1600)(.1905) \\
-(-.1190)(-.1612)=.5903 .
\end{aligned}
$$

\begin{tabular}{|c|c|c|c|c|c|c|c|c|c|c|c|}
\hline \multicolumn{6}{|c|}{ General } & \multicolumn{6}{|c|}{ Illustration } \\
\hline$x_{1}$ & $x_{2}$ & $x_{3}$ & $x_{1}$ & & check & $x_{1}$ & $x_{2}$ & $x_{3}$ & $x_{4}$ & & check \\
\hline $\begin{array}{l}a_{11} \\
a_{12} \\
a_{13} \\
a_{14} \\
1 \\
\end{array}$ & $\begin{array}{l}a_{21} \\
a_{22} \\
a_{23} \\
a_{24} \\
b_{21}\end{array}$ & $\begin{array}{l}a_{31} \\
a_{32} \\
a_{33} \\
a_{34} \\
b_{31}\end{array}$ & $\begin{array}{l}a_{41} \\
a_{42} \\
a_{43} \\
a_{44} \\
b_{41}\end{array}$ & $\begin{array}{l}a_{51} \\
a_{52} \\
a_{33} \\
a_{54} \\
b_{51}\end{array}$ & $\begin{array}{l}a_{61} \\
a_{62} \\
a_{63} \\
a_{64} \\
b_{61}\end{array}$ & $\begin{array}{r}1.0000 \\
.4000 \\
.5000 \\
.6000 \\
1.0000\end{array}$ & $\begin{array}{r}.4000 \\
1.0000 \\
.3000 \\
.4000 \\
.4000\end{array}$ & $\begin{array}{r}.5000 \\
.3000 \\
1.0000 \\
.2000 \\
.5000\end{array}$ & $\begin{array}{r}.6000 \\
.4000 \\
.2000 \\
1.0000 \\
.6000\end{array}$ & $\begin{array}{l}.2000 \\
.4000 \\
.6000 \\
.8000 \\
.2000\end{array}$ & $\begin{array}{l}2.7000 \\
2.5000 \\
2.6000 \\
3.0000 \\
2.7000\end{array}$ \\
\hline & $\begin{array}{l}a_{22.1} \\
a_{23.1} \\
a_{24.1} \\
1\end{array}$ & $\frac{a_{32.2}}{-}$ & $\begin{array}{l}a_{42.1} \\
- \\
b_{42.1}\end{array}$ & $\frac{a_{52.1}}{-}$ & $\frac{b_{62.1}}{b_{62.1}}$ & & $\begin{array}{r}.8400 \\
.1000 \\
.1600 \\
1.0000\end{array}$ & $\begin{array}{c}.1000 \\
- \\
.1190\end{array}$ & $\begin{array}{c}.1600 \\
\overline{-} \\
.1905\end{array}$ & $\begin{array}{c}.3200 \\
- \\
.3810\end{array}$ & $\begin{array}{c}1.4200 \\
- \\
1.6905\end{array}$ \\
\hline & & $\begin{array}{l}a_{33.12} \\
a_{34.12} \\
1\end{array}$ & $\frac{a_{43.12}}{b_{43.12}}$ & $\frac{a_{53.12}}{b_{53.12}}$ & $\frac{a_{63.12}}{b_{63.12}}$ & & & $\begin{array}{r}.7381 \\
-.1190 \\
1.0000\end{array}$ & $\begin{array}{c}-.1190 \\
-.1612\end{array}$ & $\begin{array}{c}.4619 \\
\frac{6258}{.}\end{array}$ & $\begin{array}{c}1.0810 \\
-\overline{4646}\end{array}$ \\
\hline & & & $a_{44.123}$ & $a_{54.123}$ & $a_{B A .128}$ & & & & .5903 & .6935 & 1.2838 \\
\hline 1 & 1 & 1 & 1 & $\begin{array}{l}b_{54.123} \\
b_{53.124} \\
b_{52.134} \\
b_{31.254}\end{array}$ & $\begin{array}{l}b_{64.123} \\
b_{63.724} \\
b_{62.186} \\
b_{61.234}\end{array}$ & 1.0000 & 1.0000 & 1.0000 & 1.0000 & $\begin{array}{r}1.1748 \\
.8152 \\
.0602 \\
-.9366\end{array}$ & $\begin{array}{r}2.1748 \\
1.8152 \\
1.0602 \\
.0634\end{array}$ \\
\hline
\end{tabular}

TABLE 4. ABBREVIATED METHOD OF SINGLE DIVISION 


\section{Method Five. Abbreviated Method of Single Division - Symmetric}

If the matrix of the coefficients is symmetric we may combine the advantages of the method of single division - symmetric and those of the abbreviated method of single division into a new method which we may call the abbreviated method of single division - symmetric. If we combine the omissions of the method of single division - symmetric (the entries below the main diagonal) and those of the abbreviated method of single division (the entries to the right of the first column and below the first row), we find that we have omissions everywhere except in the first row of each matrix (and of course the last row of each matrix which is obtained by dividing the entries of the first row of the matrix by the leading element). In this way we need record but two rows in each matrix and the number of rows and computations, if $n$ is large, is cut down enormously.

It is necessary, however, to adjust our technique for determining the products, as these products must be obtained from the entries of the twin rows of each matrix. The method of using the diagonal to locate the second entry can not now be used after the first matrix, since most of the rows of the matrix do not now appear.

However,

$$
a_{i j .1}=a_{i j}-a_{1 j} b_{i 2}=a_{i j}-a_{j_{1}} b_{i 1},
$$

TABLE 5. ABBREVIATED METHOD OF SINGLE DIVISIONSYMMETRIC

\begin{tabular}{|c|c|c|c|c|c|c|c|c|c|c|c|}
\hline \multicolumn{6}{|c|}{ General } & \multicolumn{6}{|c|}{ lllustration } \\
\hline$x_{1}$ & $x_{2}$ & $x_{3}$ & $x_{1}$ & & check & $x_{1}$ & $x_{2}$ & $x_{3}$ & $x_{4}$ & & check \\
\hline \multirow{14}{*}{$\frac{a_{11}}{-}$} & $a_{21}$ & $a_{31}$ & $a_{\mathbf{6}}$ & $a_{51}$ & $a_{61}$ & 1.0000 & .4000 & .5000 & .6000 & .2000 & 2.7000 \\
\hline & $a_{22}$ & $a_{32}$ & $a_{42}$ & $a_{52}$ & $a_{62}$ & - & 1.0000 & .3000 & .4000 & .4000 & .5000 \\
\hline & - & $a_{33}$ & $a_{43}$ & $a_{33}$ & $a_{63}$ & - & - & 1.0000 & .2000 & .6000 & .6000 \\
\hline & - & - & $a_{44}$ & $a_{54}$ & $a_{64}$ & - & - & 二 & 1.0000 & .8000 & 3.0000 \\
\hline & $b_{21}$ & $b_{31}$ & $b_{41}$ & $b_{53}$ & $b_{62}$ & 1.0000 & .4000 & .5000 & .6000 & .2000 & 2.7000 \\
\hline & $a_{22.1}$ & $a_{32.3}$ & $a_{42.1}$ & $a_{32.2}$ & $a_{62.1}$ & & .8400 & .1000 & .1600 & .3200 & 1.4200 \\
\hline & & $0_{32.1}$ & ${ }_{12.1}$ & 52. & 62 & & & & & .3810 & 1.6900 \\
\hline & & $a_{33.12}$ & $a_{13.12}$ & $a_{53.12}$ & $a_{63.12}$ & & & .7381 & -.1190 & .4619 & 1.0810 \\
\hline & & & $b_{43.12}$ & $b_{53.12}$ & $b_{63.12}$ & & & 1.0000 & -.1612 & .6258 & 1.4646 \\
\hline & & & $a_{44.123}$ & $a_{54.123}$ & $a_{64.123}$ & & & & .5903 & .6935 & 1.2838 \\
\hline & & & 1 & $b_{54.123}$ & $b_{64.123}$ & & & & 1.0000 & 1.1748 & 2.1748 \\
\hline & & 1 & & & $b_{63.124}$ & & $0 \cap 0$ & 1.0000 & & .8152 & 1.8152 \\
\hline & 1 & & & ${ }^{6} 52.13 \mathrm{t}$ & $0_{62.134}$ & & .0000 & & & .0602 & 1.0602 \\
\hline & & & & $b_{51.234}$ & $b_{81.234}$ & 1.0000 & & & & -.9366 & .0634 \\
\hline
\end{tabular}




$$
\begin{aligned}
a_{i j .12} & =a_{i j}-a_{j 1} b_{i 1}-a_{2 j .1} b_{i 2.1} \\
& =a_{i j}-a_{j 1} b_{i 1}-a_{j 2.1} b_{i 2.1}, \\
a_{i j .123} & =a_{i j}-a_{j 1} b_{i 1}-a_{j 2.1} b_{i 2.1}-a_{j 3.12} b_{i 3.12}, \text { etc., }
\end{aligned}
$$

and the $a$ 's in the products are found by taking the entry in the column whose number is the second subscript $(j)$, while the corresponding $b$ 's are found by taking the entry in the column whose number is the first subscript (i). Thus the " $a$ " entries used to compute

$$
a_{54.123}=a_{54}-a_{41} b_{51}-a_{42.1} b_{52.1}-a_{43.22} b_{43.12}
$$

are obtained from the fourth column while the corresponding " $b$ " entries are obtained from the fifth column. Entries in these columns

\begin{tabular}{|c|c|c|c|c|c|c|c|c|c|c|c|}
\hline \multicolumn{6}{|c|}{ General } & \multicolumn{5}{|c|}{ Illustration } & \multirow[b]{2}{*}{ check } \\
\hline$x_{1}$ & $x_{2}$ & $x_{3}$ & $x$ & & check & $x_{1}$ & $x_{2}$ & $x_{3}$ & $x_{4}$ & & \\
\hline $\begin{array}{l}a_{11} \\
- \\
-\end{array}$ & $\begin{array}{l}a_{21} \\
a_{22} \\
- \\
-\end{array}$ & $\begin{array}{l}a_{31} \\
a_{32} \\
a_{33} \\
\end{array}$ & $\begin{array}{l}a_{41} \\
a_{42} \\
a_{43} \\
a_{44}\end{array}$ & $\begin{array}{l}a_{512} \\
a_{52} \\
a_{53} \\
a_{56}\end{array}$ & $\begin{array}{l}a_{6 x} \\
a_{62} \\
a_{63} \\
a_{6 x}\end{array}$ & $\begin{array}{l}1.0000 \\
- \\
-\end{array}$ & $\begin{array}{c}.4000 \\
1.0000 \\
- \\
-\end{array}$ & $\begin{array}{c}.5000 \\
.3000 \\
1.0000 \\
-\end{array}$ & $\begin{array}{r}.6000 \\
.4000 \\
.2000 \\
1.0000\end{array}$ & $\begin{array}{l}.2000 \\
.4000 \\
.6000 \\
.8000\end{array}$ & $\begin{array}{l}2.7000 \\
2.5000 \\
2.6000 \\
3.0000\end{array}$ \\
\hline \multirow[t]{5}{*}{$a_{11}$} & $\begin{array}{l}a_{21} \\
b_{21}\end{array}$ & $\begin{array}{l}a_{31} \\
b_{31}\end{array}$ & $\begin{array}{l}a_{41} \\
b_{41}\end{array}$ & $\begin{array}{l}a_{s 1} \\
b_{s 1}\end{array}$ & $a_{61}$ & $\begin{array}{l}1.0000 \\
1.0000\end{array}$ & $\begin{array}{l}.4000 \\
.4000\end{array}$ & $\begin{array}{l}.5000 \\
.5000\end{array}$ & $\begin{array}{l}.6000 \\
.6000\end{array}$ & & \\
\hline & $\begin{array}{l}a_{22.1} \\
1\end{array}$ & $\begin{array}{l}a_{32.1} \\
b_{32.1}\end{array}$ & $\begin{array}{l}a_{42.1} \\
b_{42.1}\end{array}$ & $\begin{array}{l}a_{52.1} \\
b_{52.1}\end{array}$ & $a_{62.1}$ & & $\begin{array}{r}.8400 \\
1.0000\end{array}$ & $\begin{array}{l}.1000 \\
.1190\end{array}$ & $\begin{array}{l}.1600 \\
.1905\end{array}$ & $\begin{array}{l}.3200 \\
.3810\end{array}$ & $\begin{array}{l}1.4200 \\
1.6905\end{array}$ \\
\hline & & $\begin{array}{l}a_{33.12} \\
1\end{array}$ & $\begin{array}{l}a_{43.12} \\
b_{48.12} \\
\end{array}$ & $\begin{array}{l}a_{53.12} \\
b_{53.12} \\
\end{array}$ & $\begin{array}{l}a_{04.12} \\
b_{83.12}\end{array}$ & & & $\begin{array}{r}.7381 \\
1.0000\end{array}$ & $\begin{array}{l}-.1190 \\
-.1612 \\
\end{array}$ & $\begin{array}{r}.4619 \\
.6258 \\
\end{array}$ & $\begin{array}{l}1.0810 \\
1.4646 \\
\end{array}$ \\
\hline & & & $a_{4.128}$ & $a_{54.723}$ & $a_{66.128}$ & & & & .5908 & .6935 & 1.2838 \\
\hline & 1 & 1 & 1 & $\begin{array}{l}b_{54.123} \\
b_{53.124} \\
b_{52.134} \\
b_{51.234}\end{array}$ & $\begin{array}{l}b_{04.123} \\
b_{03.224} \\
b_{0.214} \\
b_{01.214}\end{array}$ & 1.0000 & 1.0000 & 1.0000 & 1.0000 & $\begin{array}{r}1.1748 \\
.8152 \\
.0602 \\
-.9366\end{array}$ & $\begin{array}{r}2.1748 \\
1.8152 \\
1.0602 \\
.0634\end{array}$ \\
\hline
\end{tabular}
can be easily outlined with the use of a ruler, straight-edge, or even a pencil.

TABLE 6. ABBREVIATED DOOLITTLE SOLUTION

If we lay a ruler to the right of column four and one to the left of column three

$$
a_{43.12}=(.2000)-(.5000)(.6000)-(.1000)(.1905)=-.1190 \text {. }
$$

The corresponding check column entry is

$$
\begin{aligned}
a_{63.12} & =2.6000-(.5000)(2.7000)-(.1000)(1.6905)=1.0810 \\
& \equiv .7381-.1190+.4619 .
\end{aligned}
$$


The method demands but $4 n-2$ rows, is very compact, and is easily carried out when thoroughly understood. The back solution is similar to that of earlier methods.

\section{Method Six. Abbreviated Doolittle Method}

The reader who is familiar with the Doolittle method (10) will recognize considerable similarity with the last method. As a matter of fact, the last method is essentially an abbreviated form of the Doolittle method. However, before presenting the Abbreviated Doolittle method, we make an adjustment in the ritual dealing with the first matrix. It would be somewhat simpler, though it would take an additional row, if the first row of the first matrix were repeated at the end of the first $n$ equation 3 just before the first row of $b$ 's is inserted. This is done in Table 6 where the Abbreviated Doolittle method is applied to the solution of equations (1) and (2).

The general remarks on method five apply here though the number of rows needed is now $4 n-1$ for the forward and back solutions.

It is customary in the conventional Doolittle solution to make the $b$ 's the negatives of the $b$ 's of the foregoing solution, but in the method outlined here the negative signs are absorbed in the technique.

The development above shows how the Abbreviated Doolittle method can be obtained as a special case of the method of single division when the matrix of the coefficients is symmetric.

The Abbreviated Doolittle method was outlined essentially by Waugh as early as 1935 (11), though he applied it to the solution of those equations involving correlations. However the idea is immediately applicable to the solution of symmetric equations in general, and, inasmuch as the method does not appear to have attained the recognition which it deserves, it is imperative that its advantages be presented in some detail.

It is possible, of course, to record every step and so to extend the Abbreviated Doolittle method to the conventional Doolittle method, but that is hardly to be recommended as the Doolittle method takes more space, more recording, and is not so accurate. The Abbreviated Doolittle method demands but $4 n-1$ rows, while the conventional Doolittle method demands $2+3+4+\cdots+n=\frac{n(n+1)}{2}-1$ additional rows or a total of $\frac{n^{2}+9 n-4}{2}$ rows. For example, Kurtz

needed 43 rows to present the six equations, the forward solution, and the back solution of his six-variable problem, while with the Abbreviated Doolittle method, this information could be presented in 23 
rows. It is obvious, too, that the abbreviated method is desirable in that it saves time used in recording, it eliminates errors which result from excessive recording, and it is theoretically more accurate in that it uses the approximation resulting from the combination of a number of operations rather than the combination of the approximations resulting from the operations. It should be emphasized, too, that the elimination of the unnecessary entries in the forward solution makes it easier to select the entries needed for the computation of the entries in the later matrices. As a matter of fact, one could hardly expect to arrive at a simpler technique than that outlined in the Abbreviated Doolittle method.

The Abbreviated Doolittle method as presented here differs from the conventional Doolittle method not only in the elimination of numerous eftries but also in the fact that the division is made by the leading element rather than by its negative. It is the opinion of the author that the division by the leading element is desirable in that (1) it makes possible the carrying on of the back solution in the same form as the computation of the forward solution with a minimum of effort and recording and (2) it preserves the relationship to the method of single division of which the Abbreviated Doolittle method is a special case.

It is advantageous, from a theoretical point of view, to know that the Abbreviated Doolittle method is a special case of the method of single division since the validity of the Abbreviated Doolittle method (and of the conventional Doolittle method itself, since this is essentially the Abbreviated Doolittle method with detailed steps recorded) follows at once from the validity of the method of single division. This is a matter of some importance when it is noted that the writers on the Doolittle method, from Doolittle himself (10) down to the present, usually content themselves with a description of the details of the solution rather than a justification of the method. A "proof" can be outlined with a happy choice of notation, but it now appears that validity of the Abbreviated Doolittle method can be demonstrated with little effort since it is a special case of the method of single division. The additional superfluous terms used in the conventional Doolittle method complicate the proof as well as the calculation.

The Doolittle method has been widely recommended as the means of solving normal equations when $n$ is greater than three and the matrix is symmetric (10), (12), (13), (14). It now appears, on theoretical as well as practical grounds, that the Abbreviated Doolittle method is to be preferred, - at least if a computing machine capable of performing $a-b c$ operations efficiently is available. 


\section{Method Seven. Method of Multiplication and Subtraction}

A method which does not involve division at all in the forward solution has lately come into prominence. For example, Rider has used it in his recent text $(15$, p. 36$)$ and Wren has recently described it (4). If we multiply the first equation of (1) by $-a_{12}$ and the second by $a_{11}$ and add, we get

$$
\begin{gathered}
\left(a_{22} a_{11}-a_{12} a_{21}\right) x_{2}+\left(a_{32} a_{11}-a_{12} a_{31}\right) x_{2} \\
+\left(a_{42} a_{11}-a_{12} a_{41}\right) x_{4} \\
=a_{52} a_{11}-a_{12} a_{51},
\end{gathered}
$$

and if we let $A_{i j .1}=a_{i j} a_{11}-a_{1 j} a_{i 1}$, this appears as

$$
A_{22.1} x_{2}+A_{32.1} x_{3}+A_{42.1} x_{4}=A_{52.1} \text {. }
$$

\begin{tabular}{|c|c|c|c|c|c|c|c|c|c|c|c|}
\hline \multicolumn{6}{|c|}{ General } & \multicolumn{6}{|c|}{ Illustration } \\
\hline$x_{1}$ & $x_{2}$ & $x_{3}$ & $x_{4}$ & & check & $x_{1}$ & $x_{2}$ & $x_{3}$ & $x_{4}$ & & check \\
\hline \multirow[t]{5}{*}{$\begin{array}{l}a_{11} \\
a_{12} \\
a_{13} \\
a_{14}\end{array}$} & $\begin{array}{l}a_{21} \\
a_{22} \\
a_{23} \\
a_{24}\end{array}$ & $\begin{array}{l}a_{31} \\
a_{32} \\
a_{33} \\
a_{34}\end{array}$ & $\begin{array}{l}a_{41} \\
a_{12} \\
a_{13} \\
a_{41}\end{array}$ & $\begin{array}{l}a_{51} \\
a_{52} \\
a_{53} \\
a_{54}\end{array}$ & $\begin{array}{l}a_{81} \\
a_{62} \\
a_{63} \\
a_{64}\end{array}$ & $\begin{array}{r}1.0000 \\
.4000 \\
.5000 \\
.6000\end{array}$ & $\begin{array}{r}.4000 \\
1.0000 \\
.3000 \\
.4000\end{array}$ & $\begin{array}{r}.5000 \\
.3000 \\
1.0000 \\
.2000\end{array}$ & $\begin{array}{r}.6000 \\
.4000 \\
.2000 \\
1.0000\end{array}$ & $\begin{array}{l}.2000 \\
.4000 \\
.6000 \\
.8000\end{array}$ & $\begin{array}{l}2.7000 \\
2.5000 \\
2.6000 \\
3.0000\end{array}$ \\
\hline & $\begin{array}{l}A_{22.1} \\
A_{23.1} \\
A_{24.1}\end{array}$ & $\begin{array}{l}A_{32.1} \\
A_{33.1} \\
A_{34.1}\end{array}$ & $\begin{array}{l}A_{42.1} \\
A_{43.1} \\
A_{44.1}\end{array}$ & $\begin{array}{l}A_{52.1} \\
A_{53.1} \\
A_{51.1}\end{array}$ & $\begin{array}{l}A_{62.1} \\
A_{63.1} \\
A_{64.1}\end{array}$ & & $\begin{array}{l}.8400 \\
.1000 \\
.1600\end{array}$ & $\begin{array}{r}.1000 \\
.7500 \\
-.1000\end{array}$ & $\begin{array}{r}.1600 \\
-.1000 \\
.6400\end{array}$ & $\begin{array}{l}.3200 \\
.5000 \\
.6800\end{array}$ & $\begin{array}{l}1.4200 \\
1.2500 \\
1.3800\end{array}$ \\
\hline & & $\begin{array}{l}A_{33.12} \\
A_{34.12}\end{array}$ & $\begin{array}{l}A_{43.12} \\
A_{44.12}\end{array}$ & $\begin{array}{l}A_{53.22} \\
A_{54.12}\end{array}$ & $\begin{array}{l}A_{63.12} \\
A_{64.12}\end{array}$ & & & $\begin{array}{r}.6200 \\
-.1000\end{array}$ & $\begin{array}{r}-.1000 \\
.5120\end{array}$ & $\begin{array}{l}.3880 \\
.5200\end{array}$ & $\begin{array}{l}.9080 \\
.9320\end{array}$ \\
\hline & & & $A_{44.123}$ & $\overline{A_{54.123}}$ & $A_{64.123}$ & & & & .30744 & .36120 & .66864 \\
\hline & 1 & 1 & 1 & $\begin{array}{l}B_{54.123} \\
B_{53.124} \\
B_{52.134} \\
B_{51.234}\end{array}$ & $\begin{array}{l}B_{64.123} \\
B_{63.124} \\
B_{62.134} \\
B_{61.234}\end{array}$ & 1.0000 & 1.0000 & 1.0000 & 1.0000 & $\begin{array}{r}1.1749 \\
.8153 \\
.0601 \\
-.9366\end{array}$ & $\begin{array}{r}2.1749 \\
1.8153 \\
1.0601 \\
.0634\end{array}$ \\
\hline
\end{tabular}

TABLE 7. METHOD OF MULTIPLICATION AND SUBTRACTION

A similar elimination involving the first and third equations gives

and similarly

$$
A_{23.2} x_{2}+A_{33.1} x_{3}+A_{43.1} x_{4}=A_{53.1} \text {, }
$$

$$
A_{24.1} x_{2}+A_{34.1} x_{3}+A_{44.1} x_{4}=A_{54.1} \text {. }
$$

The four equations in four unknowns have thus been reduced, by multiplication and subtraction, to three equations in three unkiowns. The process can be repeated with the resulting

with

$$
\begin{aligned}
& A_{33.12} x_{3}+A_{43.12} x_{4}=A_{53.12}, \\
& A_{34.12} x_{3}+A_{44.12} x_{4}=A_{34.12},
\end{aligned}
$$


Again

$$
A_{i j .12}=A_{i j .1} A_{2 z .1}-A_{i 2.1} A_{z j .1} \text {. }
$$

with

$$
A_{44.123} x_{4}=A_{54.123} \text {, }
$$

So

$$
A_{i j .123}=A_{i j .22} A_{33.12}-A_{i 3.12} A_{3 j .12} \text {. }
$$

$$
\begin{aligned}
& x_{4}=\frac{A_{54.123}}{A_{44.123}}=B_{54.123}, \\
& x_{8}=\frac{1}{A_{38.12}}\left[A_{53.12}-A_{43.12} B_{54.123}\right], \text { etc. }
\end{aligned}
$$

The forward solution is simpler and the back solution slightly more involved than methods previously presented. The back solution involves a division for each entry though there are no divisions in the forward solution. The solution demands $\frac{n(n+3)}{2}$ rows.

The chief advantage of the method is the $a b-c d$ technique which is used in getting the items in each successive matrix. Starting with a given term in a matrix, multiply by the upper left entry of the matrix and subtract the product of the entries at the top of the matrix column and the one at the left of the matrix row. The illus$t_{1}$ ation is given in Table 7 .

\section{Merhod Eight. Method of Multiplication and Subtraction-Symmetric}

If the matrix of the coefficients is symmetric, it is possible to leave the entries below the diagonal as blanks and to proceed somewhat as in method three (15, pp. 37-38). Any item in a matrix is now multiplied by the leading item in the matrix, and from this product is subtracted the product of the item heading the column with the item heading the column which is obtained by going to the left until the main diagonal is reached. The details of the numerical solution for equations (1) and (2) are given in Table 8.

Thus

and

$$
A_{43.1}=(.2000)(1.0000)-(.5000)(.6000)=-.1000
$$

$$
A_{43.12}=(-.1000)(.8400)-(.1000)(.1600)=-.1000 \text {. }
$$

Method Nine. Abbreviated Method of Multiplication and Subtraction

It is not necessary to record the entries except those in the first row and in the first column of each matrix. Each value $A_{i j} \ldots$ is then 
TABLE 8. METHOD OF MULTIPLICATION AND SUBTRACTIONSYMMETRIC

\begin{tabular}{|c|c|c|c|c|c|c|c|c|c|c|c|}
\hline \multicolumn{6}{|c|}{ General } & \multicolumn{6}{|c|}{ Illustration } \\
\hline$x_{1}$ & $x_{2}$ & $x_{3}$ & $x_{4}$ & & check & $x_{1}$ & $x_{2}$ & $x_{3}$ & $x_{4}$ & & check \\
\hline$\frac{a_{11}}{-}$ & $\begin{array}{l}a_{21} \\
a_{22} \\
-\end{array}$ & $\begin{array}{l}a_{31} \\
a_{32} \\
a_{33} \\
-\end{array}$ & $\begin{array}{l}a_{41} \\
a_{12} \\
a_{13} \\
a_{44}\end{array}$ & $\begin{array}{l}a_{51} \\
a_{52} \\
a_{53} \\
a_{54}\end{array}$ & $\begin{array}{l}a_{62} \\
a_{62} \\
a_{63} \\
a_{64}\end{array}$ & $\begin{array}{l}1.0000 \\
- \\
-\end{array}$ & $\begin{array}{c}.4000 \\
1.0000 \\
- \\
-\end{array}$ & $\begin{array}{c}.5000 \\
.3000 \\
1.0000 \\
-\end{array}$ & $\begin{array}{r}.6000 \\
.4000 \\
.2000 \\
1.0000\end{array}$ & $\begin{array}{l}.2000 \\
.4000 \\
.6000 \\
.8000\end{array}$ & $\begin{array}{l}2.7000 \\
2.5000 \\
2.6000 \\
3.0000\end{array}$ \\
\hline & $\begin{array}{l}A_{22.1} \\
-\end{array}$ & $\begin{array}{l}A_{32.1} \\
A_{33.1} \\
-\end{array}$ & $\begin{array}{l}A_{42.1} \\
A_{43.1} \\
A_{4.1}\end{array}$ & $\begin{array}{l}A_{52.1} \\
A_{53.1} \\
A_{54.1} \\
\end{array}$ & $\begin{array}{l}A_{62.1} \\
A_{63.1} \\
A_{64.1}\end{array}$ & & $\begin{array}{c}.8400 \\
- \\
-\end{array}$ & $\begin{array}{c}.1000 \\
.7500 \\
- \\
\end{array}$ & $\begin{array}{r}.1600 \\
-.1000 \\
.6400 \\
\end{array}$ & $\begin{array}{l}.3200 \\
.5000 \\
.6800 \\
\end{array}$ & $\begin{array}{l}1.4200 \\
1.2500 \\
1.3800 \\
\end{array}$ \\
\hline & & $A_{38.12}$ & $\begin{array}{l}A_{48.12} \\
A_{41.12}\end{array}$ & $\begin{array}{r}A_{53.12} \\
A_{54.12} \\
\end{array}$ & $\begin{array}{l}A_{63.12} \\
A_{64.12}\end{array}$ & & & .6200 & $\begin{array}{r}-.1000 \\
.5120 \\
\end{array}$ & $\begin{array}{l}.3880 \\
.5200\end{array}$ & $\begin{array}{r}9080 \\
.9320\end{array}$ \\
\hline & & & $A_{44.123}$ & $\overline{A_{54.123}}$ & $A_{64.123}$ & & & & .30744 & .36120 & .66864 \\
\hline 1 & 1 & 1 & 1 & $\begin{array}{c}B_{54.123} \\
B_{53.124} \\
B_{52.134} \\
B_{51.234}\end{array}$ & $\begin{array}{l}B_{64.123} \\
B_{63.124} \\
B_{62.134} \\
B_{61.234}\end{array}$ & 1.0000 & 1.0000 & 1.0000 & 1.0000 & $\begin{array}{r}1.1749 \\
.8153 \\
.0601 \\
-.9366\end{array}$ & $\begin{array}{r}2.1749 \\
1.8153 \\
1.0601 \\
.0634\end{array}$ \\
\hline
\end{tabular}

TABLE 9. ABBREVIATED METHOD OF MULTIPLICATION AND SUBTRACTION

\begin{tabular}{|c|c|c|c|c|c|c|c|c|c|c|c|}
\hline \multicolumn{6}{|c|}{ General } & \multicolumn{6}{|c|}{ Illustration } \\
\hline$x_{1}$ & $x_{2}$ & $x_{3}$ & $x_{4}$ & & check & $x_{1}$ & $x_{2}$ & $x_{3}$ & $x_{4}$ & & check \\
\hline $\begin{array}{l}a_{11} \\
a_{12} \\
a_{13} \\
a_{24} \\
\end{array}$ & $\begin{array}{l}a_{21} \\
a_{22} \\
a_{23} \\
a_{24}\end{array}$ & $\begin{array}{l}a_{31} \\
a_{32} \\
a_{33} \\
a_{34}\end{array}$ & $\begin{array}{l}a_{41} \\
a_{42} \\
a_{43} \\
a_{44}\end{array}$ & $\begin{array}{l}a_{51} \\
a_{52} \\
a_{53} \\
a_{54} \\
\end{array}$ & $\begin{array}{l}a_{61} \\
a_{62} \\
a_{63} \\
a_{64}\end{array}$ & $\begin{array}{r}1.0000 \\
4.000 \\
.5000 \\
.6000 \\
\end{array}$ & $\begin{array}{r}.4000 \\
1.0000 \\
.3000 \\
.4000 \\
\end{array}$ & $\begin{array}{r}.5000 \\
.3000 \\
1.0000 \\
.2000 \\
\end{array}$ & $\begin{array}{r}.6000 \\
.4000 \\
.2000 \\
1.0000 \\
\end{array}$ & $\begin{array}{l}.2000 \\
.4000 \\
.6000 \\
.8000 \\
\end{array}$ & $\begin{array}{l}2.7000 \\
2.5000 \\
2.6000 \\
3.0000 \\
\end{array}$ \\
\hline & $\begin{array}{l}A_{22.1} \\
A_{23.1} \\
A_{24.1} \\
\end{array}$ & $\begin{array}{l}A_{32.1} \\
- \\
\end{array}$ & $\begin{array}{l}A_{42.1} \\
- \\
-\end{array}$ & $\begin{array}{l}A_{52.1} \\
- \\
-\end{array}$ & $\begin{array}{l}A_{62.1} \\
-\end{array}$ & & $\begin{array}{l}.8400 \\
.1000 \\
.1600\end{array}$ & $\begin{array}{c}.1000 \\
- \\
-\end{array}$ & $\begin{array}{c}.1600 \\
- \\
\end{array}$ & $\begin{array}{c}.3200 \\
- \\
-\end{array}$ & $\begin{array}{c}1.4200 \\
- \\
- \\
\end{array}$ \\
\hline & & $\begin{array}{l}A_{33.12} \\
A_{34.12} \\
\end{array}$ & $A_{43.12}$ & $A_{53.12}$ & $A_{63.12}$ & & & $\begin{array}{r}.6200 \\
-.1000 \\
\end{array}$ & $\begin{array}{c}-.1000 \\
-\end{array}$ & $\begin{array}{c}.3880 \\
-\end{array}$ & .9080 \\
\hline & & & $A_{14.123}$ & $A_{54.123}$ & $A_{64.123}$ & & & & .30744 & .36120 & .66864 \\
\hline 1 & 1 & 1 & 1 & $\begin{array}{l}B_{54.123} \\
B_{53.124} \\
B_{52.134} \\
B_{51.234} \\
\end{array}$ & $\begin{array}{l}B_{64.123} \\
B_{63.124} \\
B_{62.134} \\
B_{61.234}\end{array}$ & 1.0000 & 1.0000 & 1.0000 & 1.0000 & $\begin{array}{r}1.1749 \\
.8153 \\
.0601 \\
-.9366 \\
\end{array}$ & $\begin{array}{r}2.1749 \\
1.8153 \\
1.0601 \\
.0634 \\
\end{array}$ \\
\hline
\end{tabular}


obtained by multiplying by the leading term and subtracting the appropriate product in each matrix. Thus

and

$$
\begin{aligned}
& A_{i j .1}=a_{i j} a_{11}-a_{i 1} a_{1 j}, \\
& A_{i j .12}=\left(a_{i j} a_{11}-a_{i 1} a_{1 j}\right) A_{22.1}-A_{2 j .1} A_{i 2.1},
\end{aligned}
$$

$$
A_{i j .123}=\left[\left(a_{i j} a_{12}-a_{i 1} a_{1 j}\right) A_{22.1}-A_{2 j .1} A_{i 2.1}\right] A_{33.12}-A_{3 j .12} A_{i 3.12} .
$$

The process of computation is easily carried out with a modern computing machine. The details of the solution are given in Table 9. Thus

$$
\begin{array}{r}
A_{43.12}=[(.2000)(1.0000)-(.5000)(.6000)] .8400 \\
-(.1000)(.1600)=-.1000
\end{array}
$$

and

$$
\begin{aligned}
A_{44.123} & =\{[(1.0000)(1.0000)-(.6000)(.6000)] .8400 \\
& -(.1600)(.1600)\}(.6200)-(.1000)(.1000)=.30744 .
\end{aligned}
$$

The method demands the same number of rows as method seven but fewer entries are used.

\section{Method Ten. Abbreviated Method of Multiplication and Subtraction - Symmetric}

In case the matrix is symmetric it is only necessary to record the first row of each matrix since the columnar entries duplicate the row entries. The values of the first rows of each matrix are determined from the matrices above. The multipliers are obtained by taking the products of the terms in the $i$ 'th and $j^{\prime}$ th columns. These columns may be outlined with the use of a straight-edge, though care must be taken not to cover up the first entry in the row, for this is needed for multiplication. For example, if $A_{43} \cdots$ is desired, then the entries, with the exception of the leading items, are all in column 3 and column 4 . The solution is given in Table 10 with the omission of the first row in the second matrix, the insertion of which is discussed later.

Thus

$$
\begin{aligned}
A_{4.32}=[(.2000)(1.0000)-(.5000)(.6000)](.8400) \\
-(.1000)(.1600)=-.1000
\end{aligned}
$$

and

$$
\begin{array}{r}
A_{44.123}=\left\{\left[(1.0000)(1.0000)-(.6000)^{2}\right](.8400)-(.1600)^{2}\right\} \\
\times(.6200)-(-.1000)^{2}=.30744 .
\end{array}
$$


TABLE 10. ABBREVIATED METHOD OF MULTIPLICATION AND SUBTRACTION-SYMMETRIC

\begin{tabular}{|c|c|c|c|c|c|c|c|c|c|c|c|}
\hline \multicolumn{6}{|c|}{ General } & \multicolumn{6}{|c|}{ Illustration } \\
\hline$x_{1}$ & $x_{2}$ & $x_{8}$ & $x_{4}$ & & check & $x_{1}$ & $x_{2}$ & $x_{3}$ & $x$ & & check \\
\hline $\begin{array}{l}a_{11} \\
-\end{array}$ & $\begin{array}{l}a_{21} \\
a_{22} \\
- \\
-\end{array}$ & $\begin{array}{l}a_{31} \\
a_{32} \\
a_{33} \\
-\end{array}$ & $\begin{array}{l}a_{42} \\
a_{42} \\
a_{43} \\
a_{44}\end{array}$ & $\begin{array}{l}a_{51} \\
a_{52} \\
a_{53} \\
a_{54}\end{array}$ & $\begin{array}{l}a_{61} \\
a_{62} \\
a_{63} \\
a_{64}\end{array}$ & $\begin{array}{c}1.0000 \\
- \\
-\end{array}$ & $\begin{array}{c}.4000 \\
1.0000 \\
- \\
-\end{array}$ & $\begin{array}{c}.5000 \\
.3000 \\
1.0000 \\
-\end{array}$ & $\begin{array}{r}.6000 \\
.4000 \\
.2000 \\
1.0000\end{array}$ & $\begin{array}{l}.2000 \\
.4000 \\
.6000 \\
.8000\end{array}$ & $\begin{array}{l}2.7000 \\
2.5000 \\
2.6000 \\
3.0000\end{array}$ \\
\hline$a_{11}$ & $\begin{array}{l}a_{21} \\
A_{22.1}\end{array}$ & $\begin{array}{l}a_{31} \\
A_{32.1} \\
A_{33.12}\end{array}$ & $\begin{array}{l}a_{11} \\
A_{42.1} \\
A_{43.12} \\
A_{14.128}\end{array}$ & $\begin{array}{l}a_{51} \\
A_{52.1} \\
A_{58.12} \\
A_{56.123}\end{array}$ & $\begin{array}{l}a_{61} \\
A_{62.1} \\
A_{63.12} \\
A_{64.123}\end{array}$ & 1.0000 & $\begin{array}{l}.4000 \\
.8400\end{array}$ & $\begin{array}{l}.5000 \\
.1000 \\
.6200\end{array}$ & $\begin{array}{c}.6000 \\
.1600 \\
-.1000 \\
.30744\end{array}$ & $\begin{array}{l}.2000 \\
.3200 \\
.3880 \\
.36120\end{array}$ & $\begin{array}{c}2.7000 \\
1.4200 \\
.9080 \\
.66864\end{array}$ \\
\hline 1 & 1 & 1 & 1 & $\begin{array}{l}B_{54.123} \\
B_{53.124} \\
B_{52.134} \\
B_{51.234}\end{array}$ & $\begin{array}{l}B_{64.123} \\
B_{63.124} \\
B_{62.134} \\
B_{61.234}\end{array}$ & 1.0000 & 1.0000 & 1.0000 & 1.0000 & $\begin{array}{r}1.1749 \\
.8153 \\
.0601 \\
-.9366\end{array}$ & $\begin{array}{r}2.1749 \\
1.8153 \\
1.0601 \\
.0534\end{array}$ \\
\hline
\end{tabular}

This method has not, to my knowledge, been presented before. It follows logically from the method of multiplication and subtraction just as the Abbreviated Doolittle method follows from the method of single division. This method is very compact and demands but $3 n-1$ rows of which $n$ are demanded for the statement of the problem and $\boldsymbol{n}$ for the statement of the solution. The technique of the method is easily learned. The forward solution is more compact than the Abbreviated Doolittle method while the back solution is somewhat longer owing to the fact that a final division must be made. However, there are no divisions (though there are multiplications) in the forward solution, and the actual solution, aside from the $n$ rows needed to express the problem and the $n$ rows stating the result, takes about half as much space as the Abbreviated Doolittle solution.

For those who use the method only occasionally it may be better to repeat the first row at the beginning of the second matrix (see Table 10) as we did in the Abbreviated Doolittle solution. The ritual can then be more easily remembered for it is necessary only to locate columns $i$ and $j$, to multiply $a_{i j}$ by the leading element of the first row of the second part of the solution, to subtract the product of the entries in the $i$ 'th and $j$ 'th columns in the row, to multiply the result by the leading element in the next row, to subtract the product of the elements of the $i$ th and $j$ th columns in this row, etc. The space devoted to the solution is then divided into three equal parts of $n$ rows, (1) the statement of the problem, (2) the details of the forward solution, and (3) the statement of the results. For brevity we shall refer to this method as the "compact" method. 


\section{THE SOLUTION OF RELATED EQUATIONS}

There are some additional points which should be made in connection with the solution of equations by the methods herein described. It should be noted first that the forward solution of such equations as

and

$$
\begin{aligned}
& a_{11} x_{1}+a_{21} x_{2}+a_{31} x_{3}=a_{51}, \\
& a_{12} x_{1}+a_{22} x_{2}+a_{32} x_{3}=a_{52}, \\
& a_{13} x_{1}+a_{23} x_{2}+a_{33} x_{3}=a_{53},
\end{aligned}
$$

$$
\begin{aligned}
& a_{11} x_{1}+a_{21} x_{2}=a_{31}, \\
& a_{12} x_{1}+a_{22} x_{2}=a_{32},
\end{aligned}
$$

are presented in each of the methods of solving (1). It is necessary only to cover up the fourth column and complete the back solution. For example, from the forward portion of the Abbreviated Doolittle method (Table 6), we have:

$$
\begin{array}{ll}
x_{3}=b_{53.12}, & x_{3}=.6258, \\
x_{2}=b_{22.1}-b_{32.1} b_{38.12}\left(=b_{52.13}\right), & x_{2}=.3065, \\
x_{1}=b_{51}-b_{51} b_{53.12}-b_{21} b_{52.18}, & x_{1}=-.2355 .
\end{array}
$$

Similarly, from the forward solution of Table 10, we have

$$
\begin{array}{ll}
x_{3}=\frac{A_{58.12}}{A_{53.12}}=B_{53.22}, & x_{3}=.6258, \\
x_{2}=\frac{1}{A_{22.1}}\left[A_{52.1}-A_{32.1} B_{53.22}\right]\left(=B_{52.13}\right), & x_{2}=.3065, \\
x_{1}=\frac{1}{a_{31}}\left[a_{51}-a_{31} B_{53.12}-a_{21} B_{52.13}\right] . & x_{1}=-.2355 .
\end{array}
$$

The solution is verified by substituting in the equations. Thus

$$
\begin{array}{r}
x_{1}+.4 x_{2}+.5 x_{3}=.20000 \\
.4 x_{1}+x_{2}+.3 x_{3}=.40004 \\
.5 x_{1}+.3 x_{2}+x_{3}=.60000
\end{array} \quad \text { when } \quad\left\{\begin{array}{lr}
x_{2}=-.2355 \\
x_{2}=.3065 \\
x_{3}=.6258
\end{array}\right\} \text {. }
$$

The reader is referred to Kurtz (12) for a more general discussion dealing with the solution of related equations.

\section{THE SOLUTION OF GROUPS OF EQUATIONS}

It is sometimes desired to solve groups of equations in which the variables have the same coefficients, but the constants are different. 


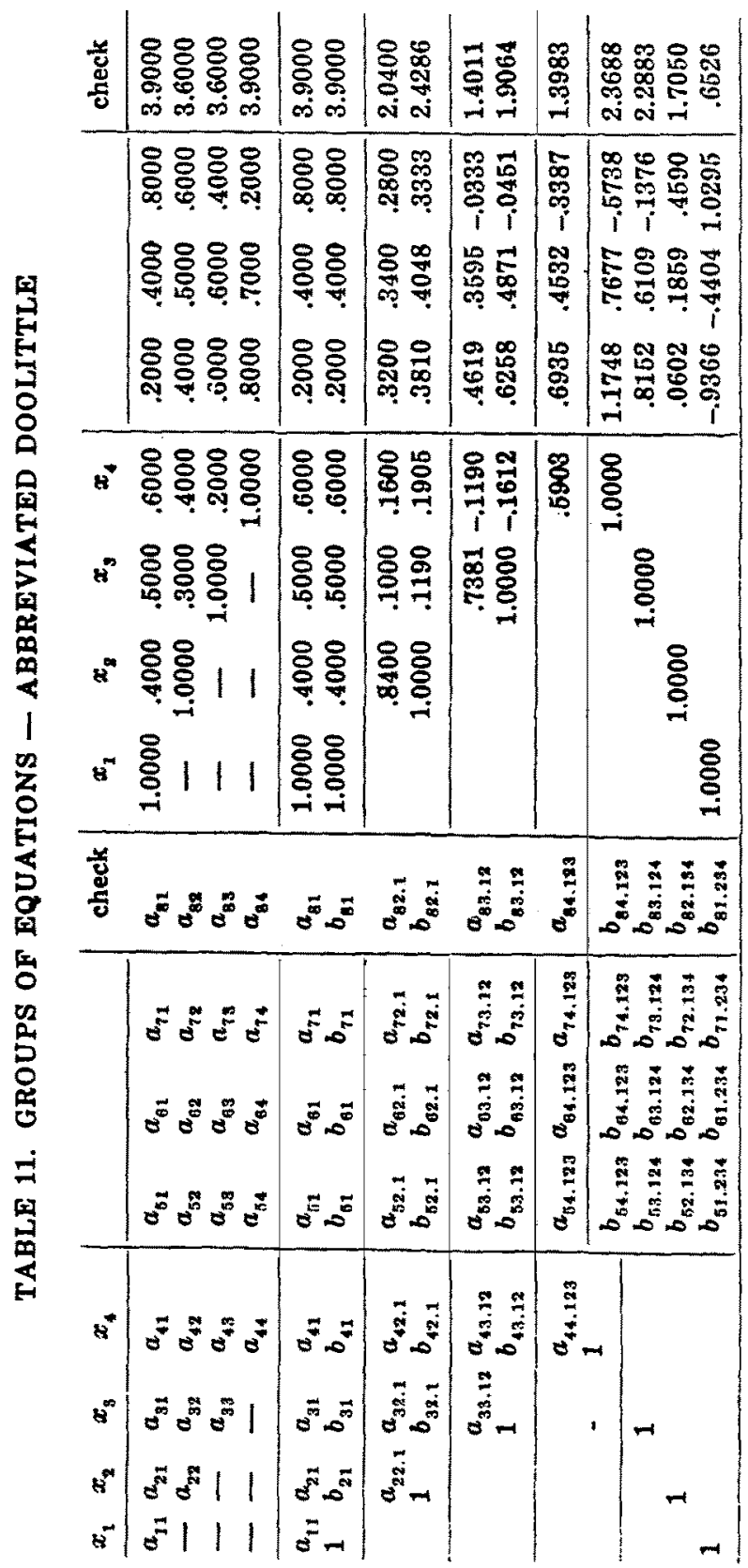




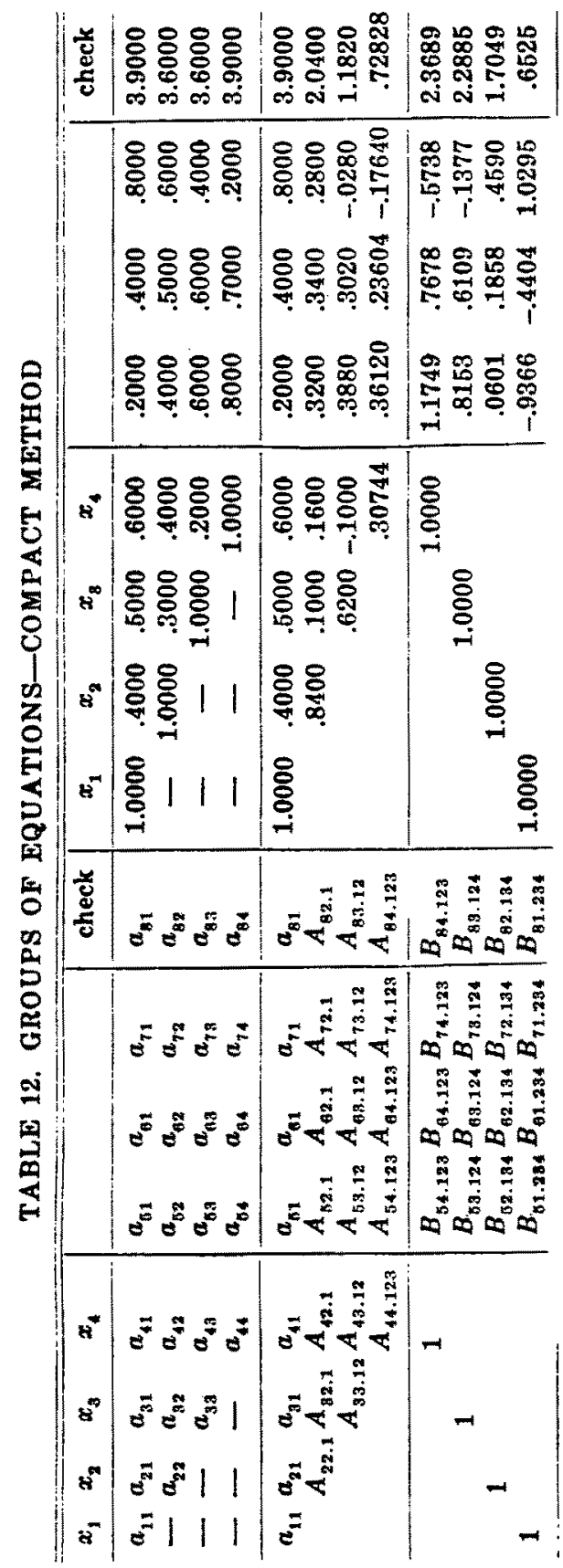


Thus the values of $a_{51}, a_{52}, a_{53}, a_{54}$, in (2) might be: (a) $.2, .4, .6$, $.8 ;(b) .4, .5, .6, .7$, and $(c) .8, .6, .4, .2$.

It is possible, in any of the solutions indicated above, to insert additional columns and to carry along the solutions simultaneously. The check column should show the sum of the entries in the row. This method is advised in case a few groups of equations are involved. The solution which uses the Abbreviated Doolittle method is given in Table 11.

The results are obtained by the more accurate "Compact" method in Table 12.

\section{The Solution of Groups of Equations - Fisher Method}

In case the number of groups is large, however, it is better to use a more general method. If each group contains $n$ equations in $n$ unknowns, a special column can be reserved for the coefficients of $a_{n+1,1}$, one for the coefficients of $a_{n+2,1}$, etc. These coefficients are either 1 or 0 and constitute a unit diagonal matrix. Thus equations (1) can be written symbolically as

\begin{tabular}{llll|lllll}
$x_{1}$ & $x_{2}$ & $x_{3}$ & $x_{4}$ & $a_{51}$ & $a_{52}$ & $a_{53}$ & $a_{34}$ & \\
\hline$a_{11}$ & $a_{21}$ & $a_{31}$ & $a_{41}$ & 1 & 0 & 0 & 0 & \\
$a_{12}$ & $a_{22}$ & $a_{32}$ & $a_{42}$ & 0 & 1 & 0 & 0 & $(8)$ \\
$a_{13}$ & $a_{23}$ & $a_{33}$ & $a_{43}$ & 0 & 0 & 1 & 0 & \\
$a_{34}$ & $a_{24}$ & $a_{34}$ & $a_{44}$ & 0 & 0 & 0 & 1 & \\
\hline
\end{tabular}

and the solution can be worked out in terms of $a_{51}, a_{52}, a_{53}, a_{54}$, by the methods just described. It is necessary only to insert any desired values of $a_{5 j}$ to obtain the solution.

It appears that this method was first outlined by R. A. Fisher (16, p. 150). It can be combined with any of the methods described above. The author has shown how it can be combined with the conventional Doolittle solution (17). In Tables 13 and 14 are presented the Abbreviated Doolittle solution and the "Compact" solution of equations (2) for any $a_{5 j}$. The check column, $a_{8 j}$ is as usual the sum of the entries in the completed row. 
TABLE 13. ABBREVIATED DOOLITTLE-FISHER METHOD

\begin{tabular}{|c|c|c|c|c|c|c|c|c|}
\hline$x_{1}$ & $x_{2}$ & $x_{3}$ & $x$ & $a_{51}$ & $a_{52}$ & $a_{53}$ & $a_{54}$ & $\begin{array}{c}\text { check } \\
a_{6 j}\end{array}$ \\
\hline 1.0000 & .4000 & .5000 & .6000 & 1 & 0 & 0 & 0 & 3.5000 \\
\hline - & 1.0000 & .3000 & .4000 & 0 & 1 & 0 & 0 & 3.1000 \\
\hline - & - & 1.0000 & .2000 & 0 & 0 & 1 & 0 & 3.0000 \\
\hline - & - & - & 1.0000 & 0 & 0 & 0 & 1 & 3.2000 \\
\hline 1.0000 & .4000 & .5000 & .6000 & 1.0000 & 0 & 0 & 0 & 3.5000 \\
\hline \multirow[t]{9}{*}{1.0000} & .4000 & .5000 & .6000 & 1.0000 & 0 & 0 & 0 & 3.5000 \\
\hline & .8400 & .1000 & .1600 & -.4000 & 1.0000 & 0 & 0 & 1.7000 \\
\hline & 1.0000 & .1190 & .1905 & -.4762 & 1.1905 & 0 & 0 & 2.0238 \\
\hline & & .7381 & -.1190 & -.4524 & -.1190 & 1.0000 & 0 & 1.0476 \\
\hline & & 1.0000 & -.1612 & -.6129 & -.1612 & 1.3548 & 0 & 1.4193 \\
\hline & & & .5903 & -.5966 & -.2097 & .1612 & 1.0000 & .9451 \\
\hline & & & 1.0000 & -1.0107 & -.3552 & .2731 & 1.6941 & 1.6011 \\
\hline & & 1.0000 & & -.7758 & -.2185 & 1.3988 & .2731 & 1.6774 \\
\hline & 1.0000 & & & -.1913 & 1.2842 & -.2185 & -.3552 & 1.5192 \\
\hline 1.0000 & & & & 2.0708 & -.1913 & -.7759 & -1.0109 & 1.0930 \\
\hline
\end{tabular}

TABLE 14. COMPACT-FISHER METHOD

\begin{tabular}{cccc|cccc|c}
\hline$x_{1}$ & $x_{2}$ & $x_{3}$ & $x_{*}$ & $a_{s 2}$ & $a_{52}$ & $a_{s 3}$ & $a_{54}$ & $\begin{array}{c}\text { check } \\
a_{6 j}\end{array}$ \\
\hline 1.0000 & .4000 & .5000 & .6000 & 1 & 0 & 0 & 0 & 3.5000 \\
- & 1.0000 & .3000 & .4000 & 0 & 1 & 0 & 0 & 3.1000 \\
- & - & 1.0000 & .2000 & 0 & 0 & 1 & 0 & 3.0000 \\
- & - & - & 1.0000 & 0 & 0 & 0 & 1 & 3.2000 \\
\hline 1.0000 & .4000 & .5000 & .6000 & 1.0000 & 0 & 0 & 0 & 3.5000 \\
& .8400 & .1000 & .1600 & -.4000 & 1.0000 & 0 & 0 & 1.7000 \\
& & .6200 & -.1000 & -.3800 & -.1000 & .8400 & 0 & .8800 \\
& & & .30744 & -.3108 & -.1092 & .0840 & .5208 & .49224 \\
\hline & & & 1.0000 & -1.0109 & -.3552 & .2732 & 1.6940 & 1.6011 \\
& & 1.0000 & & -.7759 & -.2186 & 1.3989 & .2732 & 1.6776 \\
1.0000 & 1.0000 & & & -.1913 & 1.2842 & -.2186 & -.3552 & 1.5191 \\
& & & 2.0710 & -.1913 & -.7759 & -1.0109 & 1.0929 \\
\hline
\end{tabular}

We have then

$$
\begin{aligned}
& x_{1}=2.0710 a_{51}-.1913 a_{52}-.7759 a_{53}-1.0109 a_{54} \\
& x_{2}=-.1913 a_{51}+1.2842 a_{52}-.2186 a_{53}-.3552 a_{54} \\
& x_{3}=-.7759 a_{51}-.2186 a_{52}+1.3989 a_{53}+.2732 a_{54} \\
& x_{4}=-1.0109 a_{51}-.3552 a_{52}+.2732 a_{53}+1.6940 a_{54} .
\end{aligned}
$$


The values of $a_{5 j}$ are then inserted to obtain values of $x_{i}$. For example, when $a_{52}=.2, a_{52}=.4, a_{53}=.6, a_{54}=.8$, we have

$x_{1}=-.9366, x_{2}=.0601, x_{3}=.8153, x_{4}=1.17$
and these results agree with those of Tables 11 and 12 .

\section{The Inverse of a Matrix}

The solutions just above give a method for finding the inverse of a matrix since they provide the matrix $A^{-1}$ in

$$
A A^{-1}=\mathrm{I} \text {. }
$$

The method above can be used whether $A$ is a square matrix, or not. In case $A$ is a square synmetric matrix it is possible to shorten the Fisher solution appreciably by omitting the columns on the right. The matrix $A^{-1}$ is symmetric, and this fact can be used to eliminate many of the entries. Furthermore, the intermediate equations take the form, in the "Compact" method,

$$
\begin{aligned}
a_{11} x_{1}+a_{21} x_{2}+a_{31} x_{3}+a_{41} x_{4} & =y_{1} \\
A_{22.1} x_{2}+A_{32.2} x_{3}+A_{42.12} x_{4} & =C_{12} y_{1}+a_{11} y_{2} \\
A_{38.12} x_{3}+A_{4 s .12} x_{4} & =C_{18} y_{1}+C_{23} y_{2}+a_{21} A_{22.1} y_{3} \\
A_{44.123} x_{4} & =C_{14} y_{1}+C_{24} y_{2}+C_{34} y_{3} \\
& +a_{11} A_{22.1} A_{33.12} y_{4} .
\end{aligned}
$$

It is possible to find formal expressions for the C's in terms of the $A$ 's, but the method outlined below avoids this. If the equations (10) are solved for $x_{1}, x_{2}, x_{3}, x_{4}$, we get

$$
\begin{aligned}
& x_{1}=D_{11} y_{1}+D_{21} y_{2}+D_{31} y_{3}+D_{41} y_{4} \\
& x_{2}=D_{12} y_{1}+D_{22} y_{2}+D_{32} y_{3}+D_{42} y_{4} \\
& x_{3}=D_{13} y_{1}+D_{23} y_{2}+D_{33} y_{3}+D_{43} y_{4} \\
& x_{4}=D_{14} y_{1}+D_{24} y_{2}+D_{34} y_{3}+D_{44} y_{4},
\end{aligned}
$$

where the $D$ 's form the symmetric matrix $D=A^{-1}$ with $D_{i j}=D_{j \mathrm{i}}$. Now from the last equation of (10)

$$
D_{4 t}=\frac{a_{11} A_{22.1} A_{33.12}}{A_{44.123}},
$$

so that, by solving for $D_{9 j}$ in the third, second, and first equations of (10), we get 


$$
\begin{aligned}
& D_{4}=\frac{1}{A_{23.12}}\left[-A_{48.12} D_{41}\right] \\
& D_{\star}=\frac{1}{A_{22.1}}\left[-A_{32.1} D_{43}-A_{42.1} D_{44}\right] \\
& D_{41}=\frac{1}{a_{11}}\left[-a_{21} D_{42}-a_{31} D_{43}-a_{41} D_{44}\right] .
\end{aligned}
$$

We next fill in the values $D_{14}, D_{24}, D_{34}$, since $\underline{D_{i j}}=D_{j i}$ and note

$$
\begin{aligned}
& D_{33}=\frac{1}{A_{33.12}}\left[a_{11} A_{22.1}-A_{43.12} D_{34}\right] \\
& D_{32}=\frac{1}{A_{22.1}}\left[-A_{32.1} D_{33}-A_{42.1} D_{34}\right] \\
& D_{31}=\frac{1}{a_{21}}\left[-a_{21} D_{32}-a_{31} D_{33}-A_{41} D_{34}\right]
\end{aligned}
$$

\begin{tabular}{|c|c|c|c|c|c|c|c|}
\hline 1.0000 & .4000 & .5000 & .6000 & & & & \\
\hline- & 1.0000 & .3000 & .4000 & & & & \\
\hline- & - & 1.0000 & .2000 & & & & \\
\hline - & - & - & 1.0000 & & & & \\
\hline \multirow[t]{4}{*}{1.0000} & .4000 & .5000 & .6000 & 2.0710 & -.1913 & -.7759 & -1.0109 \\
\hline & $\begin{array}{c}(1.0000) \\
.8400\end{array}$ & .1000 & .1600 & -.1913 & 1.2842 & -.2186 & -.3552 \\
\hline & & $\begin{array}{c}(.8400) \\
.6200\end{array}$ & -.1000 & -.7759 & -.2186 & 1.3989 & .2732 \\
\hline & & & $\begin{array}{r}(.5208) \\
.30744\end{array}$ & -1.0109 & -.3552 & .2732 & 1.6940 \\
\hline
\end{tabular}

with $D_{13}=D_{31}, D_{12}=D_{21}$.

Similarly,

$$
\begin{aligned}
D_{22} & =\frac{1}{A_{22.1}}\left[a_{11}-A_{32.1} D_{23}-A_{24.1} D_{24}\right] \\
D_{21}\left(=D_{22}\right) & =\frac{1}{a_{13}}\left[-a_{21} D_{22}-A_{31} D_{23}-a_{41} D_{24}\right] \\
D_{11} & =\frac{1}{a_{11}}\left[1-a_{21} D_{12}-a_{31} D_{13}-a_{41} D_{14}\right] .
\end{aligned}
$$

TABLE 15(a). THE INVERSE OF A SQUARE SYMMETRIC MATRIX. COMPACT METHOD 
An illnstration is given in Table 15 (a) where the compact method is used.

The first four columns are characteristic of the forward solution of the compact method. In addition, in the diagonal of the second matrix, I have inserted in parentheses the values, $1, a_{11}, a_{11} A_{22.1}, a_{11} A_{22.1}$ $\times A_{38.12}$. It follows at once that

$$
\begin{gathered}
D_{44}=\frac{.5208}{.30744}=1.6940 ; D_{43}=\frac{1}{.6200}[-(-.1000)(1.6940)]=.2732 \\
D_{33}=\frac{1}{.6200}[.8400-(-.1000)(.2732)], \text { etc. }
\end{gathered}
$$

The method is not at all difficult to apply once the formulas above are thoroughly understood. The type of operation is similar to that used in the usual back solution.

An alternative method is provided in Table $15(\mathrm{~b})$ where the first two matrices agree with those of Table 15(a). As before, $D_{44}=$ $\frac{.5208}{.30744}=1.6940$ and $D_{43}=\frac{1}{.6200}[-(-.1000)(1.6940)]=.2732$.

The value $D_{34}=.2732$ is then inserted and the value of $D_{42}$ found, essentially, by taking products of terms in the same columns. The

TABLE 15(b). THE INVERSE OF A SQUARE SYMMETRIC MATRIX.

\begin{tabular}{|c|c|c|c|}
\hline 1.0000 & .4000 & .5000 & .6000 \\
\hline - & 1.0000 & .3000 & .4000 \\
\hline- & - & 1.0000 & .2000 \\
\hline- & - & - & 1.0000 \\
\hline \multirow[t]{4}{*}{1.0000} & .4000 & .5000 & .6000 \\
\hline & $\begin{array}{c}(1.0000) \\
8400\end{array}$ & .1000 & .1600 \\
\hline & & $\begin{array}{c}(.8400) \\
.6200\end{array}$ & -.1000 \\
\hline & & & $\begin{array}{r}(.5208) \\
.30744\end{array}$ \\
\hline 2.0710 & -.1913 & -.7759 & -1.0109 \\
\hline-.1913 & 1.2842 & -.2186 & -.3552 \\
\hline-.7759 & -.2185 & 1.3989 & .2732 \\
\hline-1.0109 & -.3552 & .2732 & 1.6940 \\
\hline
\end{tabular}
COMPACT METHOD 
general idea is to get the higher vertical terms in each column and, as soon as one is available, write it in the proper row so that the next element can be found. When all the elements in a given row are found, move on to the next row, etc. This, too, is a simple technique once it is thoroughly understood.

A similar scheme can be worked out for the Abbreviated Doolittle method. In this case the intermediate equations have the form

$$
\begin{aligned}
x_{1}+b_{21} x_{2}+b_{81} x_{3}+b_{41} x_{4} & =\frac{1}{a_{12}} y_{1} \\
x_{2}+b_{20.1} x_{3}+b_{42.1} x_{4} & =E_{12} y_{1}+\frac{1}{a_{22.1}} y_{2} \\
x_{3}+b_{43.12} x_{4} & =E_{13} y_{1}+E_{23} y_{2}+\frac{1}{a_{33.12}} y_{3} \\
x_{4} & =E_{24} y_{1}+E_{24} y_{2}+E_{34} y_{3}+\frac{1}{a_{44.123}} y_{4}
\end{aligned}
$$

so that

$$
\begin{aligned}
& D_{44}=\frac{1}{a_{46.23}}, D_{43}=-b_{43.12} D_{44}=D_{34} \\
& D_{42}=-\left(b_{82.1} D_{43}+b_{42.1} D_{44}\right)=D_{24} \\
& D_{41}=-\left(b_{21} D_{42}+b_{31} D_{43}+b_{41} D_{44}\right)=D_{14} \\
& D_{34}=\frac{1}{a_{33.12}}-b_{43.12} D_{34}, \text { etc. }
\end{aligned}
$$

The numerical illustration is given in Table 16 , where the two alternative solutions are shown. The values $\frac{1}{a_{11}}, \frac{1}{a_{22.1}}, \frac{1}{a_{33.12}}, \frac{1}{a_{46.123}}$ are inserted above $a_{11}, a_{22.1}, a_{33.12}, a_{44.123}$. The first solution on the right is similar to the solution in Table 15 (a) while the second solution at the bottom is similar in method to the solution of Table 15 (b).

This version of the method for finding the inverse of a square symmetric matrix has been given, essentially, by Waugh (11) who made improvements on the technique previously worked out by Horst (18) (19). Waugh used the Abbreviated Doolittle method and applied it to the correlation matrix and showed how to compute the large number of statistical quantities which can be computed from the inverse of the correlation matrix. Dunlap (20, pp. 119-123) has presented a similar method which he attributes to Cureton. 
TABLE 16. THE INVERSE OF A SQUARE SYMMETRIC MATRIXABBREVIATED DOOLITTLE METHOD

\begin{tabular}{|c|c|c|c|c|c|c|c|}
\hline 1.0000 & .4000 & .5000 & .6000 & & & & \\
\hline - & 1.0000 & .3000 & .4000 & & & & \\
\hline - & - & 1.0000 & .2000 & & & & \\
\hline - & - & - & 1.0000 & & & & \\
\hline 1.0000 & .4000 & .5000 & .6000 & & & & \\
\hline$(1.0000)$ & & & & & & & \\
\hline \multirow[t]{6}{*}{1.0000} & .4000 & .5000 & .6000 & 2.0710 & -.1913 & -.7759 & -1.0109 \\
\hline & .8400 & .1000 & .1600 & & & & \\
\hline & $\begin{array}{c}(1.1905) \\
1.0000\end{array}$ & 1190 & 1905 & -1913 & 12842 & -2185 & $355 ?$ \\
\hline & & .7381 & -.1190 & & & & \\
\hline & & $\begin{array}{c}(1.3548) \\
1.0000\end{array}$ & -.1612 & -.7759 & -.2185 & 1.3988 & .2731 \\
\hline & & & $\begin{array}{c}(1.6941) \\
.5903\end{array}$ & -1.0109 & -.3552 & .2731 & 1.6941 \\
\hline 2.0710 & -.1913 & -.7759 & -1.0109 & & & & \\
\hline-.1913 & 1.2842 & -.2185 & -.3552 & & & & \\
\hline-.7759 & -.2185 & 1.3988 & .2731 & & & & \\
\hline-1.0109 & -.3552 & .3731 & 1.6941 & & & & \\
\hline
\end{tabular}

Other methods of finding the inverse of a matrix have been published recently (9) (21). These combine one of the methods outlined at the beginning of the paper with a scheme, which seems to be due to Aitken (9), which carries out the back solution by "forward" means.

\section{Solution of Non-Symmetric Equations by Symmetric Methods}

Aitken has shown (9) that it is possible to reduce non-symmetric equations to equivalent symmetric equations. If the equations are represented by $A x=B$, then by premultiplying by $A^{\prime}$ we have the equivalent

with $A^{\prime} A$ a symmetric matrix.

$$
A^{\prime} A x=A^{\prime} B \text {, }
$$

\section{Conclusion}

Various known methods of solving equations have been presented in such a fashion as to bring out their relations with other methods. By gradual steps the method of single division leads to an abbreviated 
version of the Doolittle method while, by corresponding steps, the method of multiplication and subtraction leads to a new compact method. These methods are applied to such problems as the solution of groups of equations and the evaluation of the inverse of a matrix. The evaluation of determinants, of multiple correlation coefficients, of regression coefficients, of linear forms, etc., will be discussed in later papers.

The bibliography attached, while extensive, does not pretend to be complete. Some of the references themselves provide extensive bibliography and, in this way, it is possible to contact, from the references below, much of the work done in this field.

\section{REFERENCES}

1. Salisbury, F. S. A simplified method of computing multiple correlation constants. J. educ. Prych., 1929, 20, 44-52.

2. Griffin, H. D. On partial correlation versus partial regression for obtaining the multiple regression equations. J. educ. Psych., 1931, 22, 35-44. (Particularly valuable for the bibliography.)

3. Thompson, G. H. Some points of mathematical technique in the factorial analysis of ability. J. educ. Psych., 1936, 27, 37-54.

4. Wren, F. L. The calculation of partial and multiple coefficients of regression and correlation. J. educ. Psych., 1938, 29, 695-700.

5. Euntington, E. V. Curve-fitting by the method of least squares and the method of moments. Handbook of mathematical statistics. Chap. IV. New York: Houghton Mifflin Co.

6. Brolyer, C. R. Another short method for calculating $\beta$ weights and the resulting multiple $R$ on a computing machine. J. gen. Psych., 1933, 8, 278-281.

7. Chauncey, Henry. A method for solving simaltaneous equations, with particular reference to multiple correlation problems. Harvard educ. Rev. 1939, 9, 63-68.

8. Deming, H. G. A systematic method for the solution of simultaneous linear equations. Amer. math. Monthly, 1928, 35, 360-363.

9. Aitken, A. C. Studies in practical mathematics. I. The evaluation, with applications, of a certain triple product matrix. Proc. Royal Soc., Edinburgh, 1937, 57, 172-181.

10. Doolittle, M. H. Method employed in the solution of normal equations and the adjustment of a triangulation. U. S. Coast and Geodetic Survey Report, $1878,115-120$.

11. Wangh, F. V. A simplified method of determining multiple regression constants. J. Amer. Stut. Assoc., 1935, 30, 694-700.

12. Kurtz, A. K. The use of the Doolittle method in obtaining related multiple correlation coefficients. Psychometrika, 1936, 1, 45-51.

13. Tolley, H. R. and Ezekial, Mordecai. The Doolittle method for solving multiple correlation equations versus the Kelley-Salisbury iteration method. J. Amer. Stat. Assoc., 1927, 22, 497-500. (Particularly valuable for bibliography.)

14. Kelley, T. L. and MeNemar, O. Doolittle versus Kelley-Salisbury methods 
for computing multiple regression coefficients. J. Amer. Stat. Assoc., 1929, 24, 164-169.

15. Rider, P. R. An introduction to modern statistical methods. New York: John Wiley and Sons, 1939.

16. Fisher, R. A. Statistical methods for research workers. Fifth Edition. London: Oliver and Boyd, 1934.

17. Dwyer, P. S. The simultaneous computation of groups of regression equations and associated multiple correlation coefficients. Annals math Stat., 1937, 8, 224-231.

18. Horst, Paul. A short method for solving for a coefficient of multiple correlation. Annals math. Stat., 1932, 3, 40-44.

19. Horst, Paul. A general method for evaluating multiple regression constants. J. Amer. Stat. Assoc., 1932, 27, 270-278.

20. Dunlap, J. W. Workbook in statistical method. New York: Prentice Hall, Inc., 1939. (Note bibliography.)

21. Tucker, L. R. A method for finding the inverse of a matrix. Psychometrika, 1938, 3, 189-197.

22. Gauss, C. F. Supplementum theoriae combinationis observationum erroribus minimis obnoxiae. Werke, Band 15, 1873.

23. Schott, C. A. The solution of normal equations by indirect elimination. U. S. Coast and Geodetic Survey Report, 1855, 255-264.

24. Carr, G. S. A synopsis of elementary results in pure mathematics. London: Francis Hodgson, 1886, $\mathrm{p} .42$.

25. Merriman, M. Text book in method of least squares. New York: John Wiley and Sons, 1884, 51-59.

26. Whittaker, E. T. and Robinson, G. The calculus of observations. London: Blackie and Son, 1924, 231-239.

27. Wren, F. L. Neo-Sylvester contractions and the solution of systems of linear equations. Bull. A mer. math Soc., 1937, 43, 823-834.

28. Wherry, R. J. A modification of the Doolittle method: A logarithmic solution. J. educ. Psych., 1932, 23, 455-459. 